This item was submitted to Loughborough's Research Repository by the author.

Items in Figshare are protected by copyright, with all rights reserved, unless otherwise indicated.

\title{
Dust source identification using MODIS: a comparison of techniques applied to the Lake Eyre Basin, Australia
}

PLEASE CITE THE PUBLISHED VERSION

PUBLISHER

(C) Elsevier

VERSION

AM (Accepted Manuscript)

LICENCE

CC BY-NC-ND 4.0

\section{REPOSITORY RECORD}

Baddock, Matthew C., Joanna E. Bullard, and Robert G. Bryant. 2019. "Dust Source Identification Using MODIS: A Comparison of Techniques Applied to the Lake Eyre Basin, Australia”. figshare. https://hdl.handle.net/2134/4523. 
This item was submitted to Loughborough's Institutional Repository (https://dspace.lboro.ac.uk/) by the author and is made available under the following Creative Commons Licence conditions.

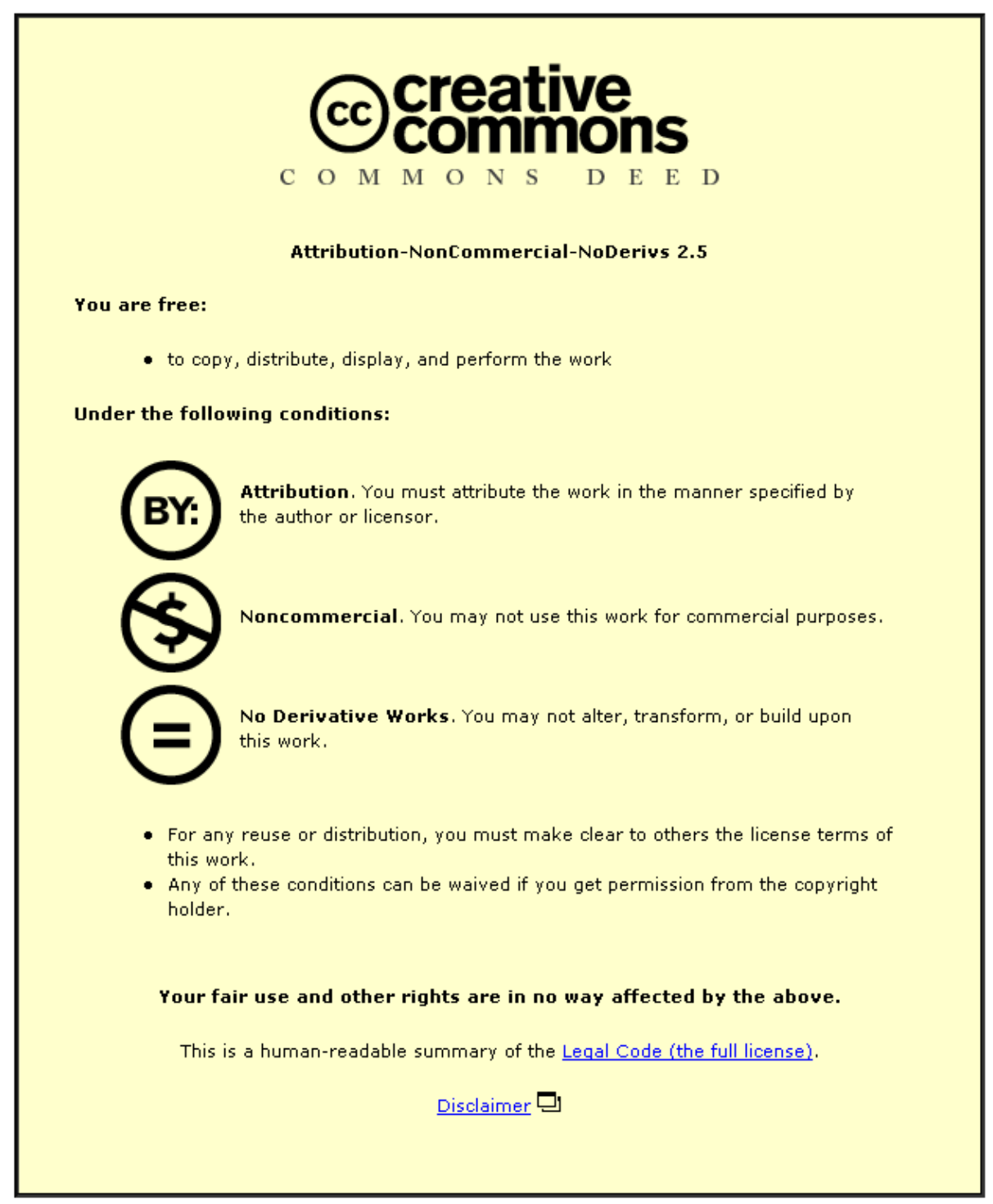

For the full text of this licence, please go to: http://creativecommons.org/licenses/by-nc-nd/2.5/ 
1 To be cited as: Baddock, M.C., Bullard, J.E., Bryant, R.G. 2009. Dust source

2 identification using MODIS: a comparison of techniques applied to the Lake

3 Eyre Basin, Australia, Remote Sensing of Environment,

4 doi:10.1016/j.rse.2009.03.002

\section{Dust source identification using MODIS: a comparison of techniques} applied to the Lake Eyre Basin, Australia

${ }^{a}$ Matthew C. Baddock,. ${ }^{a *}$ Joanna E. Bullard, and ${ }^{b}$ Robert G. Bryant.

aDepartment of Geography, Loughborough University, Loughborough, Leicestershire, LE11 3TU UK.

${ }^{\mathrm{b}}$ Department of Geography, The University of Sheffield, Western Bank, Sheffield, S10 2TN UK

* Corresponding author

\section{Abstract}

The impact of mineral aerosol (dust) in the Earth's system depends on particle characteristics which are initially determined by the terrestrial sources from which the sediments are entrained. Remote sensing is an established method for the detection and mapping of dust events, and has recently been used to identify dust source locations with varying degrees of success. This paper compares and evaluates five principal methods, using MODIS Level 1B and MODIS Level 2 aerosol data, to: (a) differentiate dust (mineral aerosol) from non-dust, and (2) determine the extent to which they enable the source of the dust to be discerned. The five MODIS L1B methods used here are: (1) un-processed false colour composite (FCC), (2) brightness temperature difference, (3) Ackerman's (1997: J.Geophys. Res., 102, 17069-17080) procedure, (4) Miller's (2003:Geophys. Res. Lett. 30, 20, art.no.2071) dust enhancement algorithm and (5) Roskovensky and Liou's (2005: Geophys. Res. Lett. 32, L12809) dust differentiation algorithm; the aerosol product is MODIS Deep Blue (Hsu et al., 2004: IEEE Trans. Geosci. Rem. Sensing, 42, 557-569), which is optimised for use over bright surfaces (i.e. deserts). These 
34 are applied to four significant dust events from the Lake Eyre Basin, Australia.

35 OMI Al was also examined for each event to provide an independent 36 assessment of dust presence and plume location. All of the techniques were 37 successful in detecting dust when compared to FCCs, but the most effective 38 technique for source determination varied from event to event depending on 39 factors such as cloud cover, dust plume mineralogy and surface reflectance. 40 Significantly, to optimise dust detection using the MODIS L1B approaches, 41 the recommended dust/non-dust thresholds had to be considerably adjusted 42 on an event by event basis. MODIS L2 aerosol data retrievals were also found 43 to vary in quality significantly between events; being affected in particular by 44 cloud masking difficulties. In general, we find that OMI Al and MODIS AQUA 45 L1B and L2 data are complementary; the former are ideal for initial dust 46 detection, the latter can be used to both identify plumes and sources at high 47 spatial resolution. Overall, approaches using brightness temperature 48 difference (BT10-11) are the most consistently reliable technique for dust 49 source identification in the Lake Eyre Basin. One reason for this is that this 50 enclosed basin contains multiple dust sources with contrasting geochemical 51 signatures. In this instance, BTD data are not affected significantly by 52 perturbations in dust mineralogy. However, the other algorithms tested 53 (including MODIS Deep Blue) were all influenced by ground surface 54 reflectance or dust mineralogy; making it impossible to use one single MODIS 55 L1B or L2 data type for all events (or even for a single multiple-plume event). 56 There is, however, considerable potential to exploit this anomaly, and to use 57 dust detection algorithms to obtain information about dust mineralogy. 


\section{Introduction}

Atmospheric mineral aerosols (termed here dust) play an important role in the land-atmosphere-ocean system (Ridgwell, 2002; Jickells et al., 2005; Waeles et al., 2007). For example, they affect soil nutrients at source and sink (McTainsh \& Strong, 2007; Muhs et al., 2007; Li et al., 2007; Reynolds et al., 2006; Soderberg \& Compton, 2007; Swap et al., 1992; Wang et al., 2006), the radiative forcing of the atmosphere (Haywood \& Boucher, 2000; Hsu et al., 2000; Satheesh \& Moorthy, 2005; Yoshioka et al., 2007) and may regulate phytoplankton activity of oceans (de Baar et al., 2005; Erickson et al., 2003; Mackie et al., 2008; Piketh et al., 2000; Wolff et al., 2006). The impact of dust in the Earth's system depends on characteristics such as particle size, shape and mineralogy (in particular iron content: Jickells et al., 2005; Mahowald et al., 2005). Whilst these characteristics can change during dust transport (Desboeufs, 2005; Mackie et al., 2005) they are initially determined by the terrestrial sources from which the particles are entrained.

The detection and mapping of dust events and dust transport pathways has benefited greatly from the use of remote sensing, and at the global scale major dust source regions have been identified using satellite data, such as from the Total Ozone Mapping Spectrometer (TOMS; Prospero et al., 2002; Washington et al., 2003). The passage of dust along specific regional transport pathways over land and ocean and the behavior of individual dust events have also been tracked using TOMS and OMI (Ozone Monitoring Instrument; e.g. Alpert et al. 2004) and at higher temporal and spatial resolutions using data from, amongst others, AVHRR (Advanced Very High Resolution Radiometer; e.g., Evan et al., 2006; Zhu et al., 2007), GOESVISSR (Geostationary Operational Environmental Satellite, Visible Infra-Red Spin-Scan Radiometer, e.g., MacKinnon et al., 1996), METEOSAT (e.g.,

92 Spectroradiometer, e.g., Badarinath et al., 2007; Gassó \& Stein, 2007; Page | 3 
93 Kaskaoutis et al. 2008; McGowan \& Clark, 2008; Zha \& Li, 2007), MSG-

94 SEVIRI (Meteosat Second Generation-Spinning Enhanced Visible and

95 InfraRed Imager; e.g., Schepanski et al., 2007) and SeaWIFS (Sea-viewing

96 Wide Field-of-View Sensor; e.g., Eckardt \& Kuring, 2005). Sensor-retrieved

97 parameters (such as MODIS aerosol size parameters; Dubovik et al., 2008;

98 Jones \& Christopher, 2007; Kaufman et al. 2005) or complex statistical

99 analyses (such as Principal Component Analysis; e.g. Argarwal et al. 2007;

100 Jones \& Christopher, 2008; Zubko et al. 2007) have also been used to

101 differentiate dust and non-dust with some success.

102

103 Systematic determination of both the geomorphological and 104 geochemical variability of dust sources, and hence the variability of the 105 sediments which are entrained and transported, requires as accurate and 106 precise an identification of the upwind (source) end of the dust plume as 107 possible. Researchers have recently started to use remote sensing data to 108 achieve this (e.g., Bullard et al., 2008; Lee et al., 2008; Zhang et al., 2008), 109 but with varying levels of success. The ability to use remotely-sensed data 110 both to detect a dust plume and identify the location from which it has 111 originated is affected by several factors including the radiative transfer 112 properties of the material emitted, the radiative properties of the ground/ocean 113 surface over which the plume is transported, the size and density of the dust 114 plume, the time of satellite overpass relative to dust emission, the presence or 115 absence of cloud, the horizontal and vertical plume trajectory, and the sensor 116 characteristics and radiative transfer model used to detect dust. In many 117 respects, the relative impacts of these factors on dust source determination 118 are hard to determine without close reference to surface meteorological data 119 (e.g. wind speed and visibility records) and ground-based aerosol 120 determination records (e.g. AERONET - Aerosol Robotic Network) which can 121 allow comparative characterisation of individual dust events (e.g. Bullard et 122 al., 2008; Mahowald et al., 2007). Even where these records exist, the direct 123 comparison of ground and remote sensing data retrievals to determine dust 124 sources can be problematic, with some remote sensing data products being 125 unable consistently to detect dust events due to the factors listed above; 126 particularly the presence of cloud, and the existence of low contrast between Page | 4 
127 dust plume and ground/ocean surface (e.g. Gassó \& Stein, 2007; Bullard et 128 al., 2008). The principal aim of this paper is to evaluate in detail the use of 129 MODIS data, one of the most widely and successfully-used sensors, for 130 improved identification of dust source locations. This paper varies in emphasis 131 from many previous studies because the focus is on the precision with which 132 the upwind (source) location of the plume can be discerned, rather than on 133 the simple determination of plume location, density and trajectory. 134 Specifically, we compare five methods of using MODIS Level 1 band data and 135 one MODIS Level 2 aerosol product and evaluate them in terms of: (a) how 136 well they enable the differentiation of dust and non-dust (cloud, smoke, 137 volcanic aerosols) and, (b) the extent to which it is possible to discern the 138 location of the dust source (i.e. the upwind part of the dust plume - or 'dust 139 head') and how much this varies from method to method. The influence of 140 environmental factors such as plume density and mineralogy on source 141 detection by MODIS will also be evaluated.

\section{Data and Methods}

\subsection{Data}

Mineral aerosol (dust) can be detected and mapped through remote sensing via inversion of radiative transfer models which operate in the following wavelengths: (a) ultraviolet (UV 0.315-0.4 $\mu \mathrm{m}$ ) via absorption (e.g.

150 TOMS Al; Torres et al., 1998), (b) visible (VIS 0.38-79 $\mu \mathrm{m}$ ) via scattering (e.g. 151 Tanré and Legrand, 1991), and (c) thermal infrared (TIR 8-15 $\mu \mathrm{m}$ ) via 152 contrasting land/aerosol emissivity and/or temperature (e.g. Ackerman, 1997).

153 Due to constraints of sensor design, observations by remote sensing systems 154 operating in VIS wavelengths can be determined at higher resolution (pixel 155 size $=x$ ) than those made in the TIR (pixel size $\left.=x^{\star} 2-4\right)$ and UV (pixel size $=$ $\left.156 x^{*} 100-200\right)$, and this has implications for both plume and source detection 157 using these approaches. Radiative transfer model inversion of aerosol 158 observations made within (or via combinations of) each of the three 159 wavelength ranges often provides either a relative indication of aerosol 160 concentration (e.g. via TOMS AI), or a calibrated (e.g. through comparison Page | 5 
161 with AERONET observations) measure of wavelength-dependent total aerosol 162 optical thickness/depth (AOT/D). The success of the radiative transfer model 163 inversion in each case is often complicated by factors such as the non164 spherical nature of the mineral aerosol, changes in the chemical/physical 165 nature of the material, and location within the atmosphere during transport. In 166 addition, over very bright surfaces (e.g. desert regions and urban areas), in 167 the presence of cloud, and at night, mineral aerosol detection using 168 UV/VIS/TIR wavelengths can become increasingly uncertain (e.g. Kaufman et 169 al., 2000). The short-term nature of some mineral aerosol events (often <1 170 day) also means that an understanding of any bias associated with mineral 171 aerosol detection at the time of satellite over-passes and temporal sampling 172 (i.e. either am or pm data collection time) is needed in order to characterize 173 fully the emission and transport process. In order to evaluate, compare and 174 contrast mineral aerosol detection approaches, a range of remote sensing 175 data are used here (see Table 1).

$<$ Insert Table 1>

\subsubsection{MODIS Data}

Data from the Moderate Resolution Imaging Spectroradiometer (MODIS) were used to make comparisons of retrievals using VIS and TIR (often combined) approaches. MODIS makes observations using 36 spectral bands with wavelengths from 0.41 to $14.4 \mu \mathrm{m}$ and nadir spatial resolutions of $0.25 \mathrm{~km}, 0.5 \mathrm{~km}$, and $1 \mathrm{~km}$. It is currently operating onboard the NASA Earth Observing System (EOS) Terra and Aqua satellites, launched in December 1999 and May 2002, respectively. Daily MODIS Level 1B (L1B) 1 km data (MOD021KM = Terra, and MYD021KM = Aqua) used in this work have been processed to convert the sensor's on-orbit responses in digital numbers to radiometrically calibrated and geo-located data products (v5.06 processing for Terra and v5.07 for Aqua). Data were obtained from the Level 1 and Atmosphere

$$
\text { Archive }
$$
and

Distribution

System

(LAADS;

192 http://ladsweb.nascom.nasa.gov/). Details of images dates and subsequent processing of MODIS L1B data are outlined below. 
Daily MODIS Level 2 Aerosol data are produced at the spatial resolution of a $10 \times 10 \mathrm{~km}$ (at nadir) pixel array. There are two MODIS Aerosol data product file types: MOD04_L2, containing data collected from the Terra platform and MYD04_L2, containing data collected from the Aqua platform. Here we only use the MYD04 Aqua product because to date Deep Blue (see

200 below) retrievals are not yet available for MOD04 Terra data. Aerosol 201 properties within MYD04_L2 are derived by the inversion of MODIS observed 202 reflectances at $500 \mathrm{~m}$ resolution using pre-computed radiative transfer look-up 203 tables based on dynamical aerosol models (Kaufman et al., 1997; Remer et 204 al., 2005). Derivation of aerosol from these data is far from straightforward 205 and, in initial versions of the MODIS aerosol product, the ability to retrieve 206 aerosol optical thickness (AOT) and single scattering albedo over bright207 reflecting surfaces has been problematic because the algorithm relies in part 208 on the initial detection of dark surfaces or targets (Kaufman et al., 2000). In 209 addition, the cloud screening has been shown to have problems where mis210 identification of some dust plumes as cloud has led to artifacts in the final data 211 (e.g. as noted by Brindley and Ignatov, 2006). These products have been 212 under continued and careful evaluation and development, and product 213 MYD04 (see http://modis214 atmos.gsfc.nasa.gov/C005_Changes/C005_Aerosol_5.2.pdf) has recently 215 received an improved aerosol determination (via reprocessing to collection 216 5.1/2; Levy et al., 2006, 2007; Remer et al., 2006) over bright surfaces 217 through the integration of a revised determination of AOT over land (Levy et 218 al., 2007), and inclusion of the Deep Blue algorithm (Hsu et al., 2004; Hsu et 219 al., 2006). Here we evaluate the Deep Blue algorithm, which relies on the blue 220 wavelengths and libraries of surface reflectance to make retrievals over bright 221 surfaces (Hsu et al., 2004).

The Deep Blue processing approach involves the following processing 224 elements: (1) Rayleigh Correction for Terrain Elevation in the following

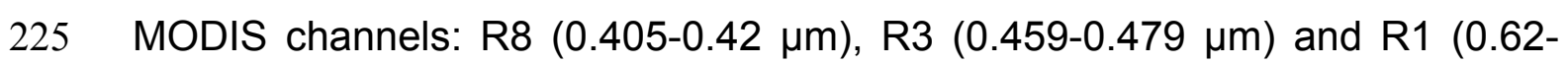
$2260.67 \mu \mathrm{m})$; (2) Cloud Screening using: R8 (3 x 3 pixel spatial variance) and $227 \mathrm{R} 3 / \mathrm{R} 8 \mathrm{Al}$; (3) the surface reflectance for a given pixel is determined from a 228 clear-scene database based upon its geo-location; (4) R8, R3 and R1 Page | 7 
229 reflectances are then compared to radiances contained in a lookup table with

230 dimensions consisting of solar zenith, satellite zenith, and relative azimuth 231 angles, surface reflectance, AOT, and single scattering albedo; (5) a 232 maximum likelihood method is used to compute a mixing ratio between dust 233 and smoke models until the calculated spectral reflectances make the best 234 match with those that are measured; and (6) for mixed aerosol conditions, 235 once the aerosol models and the mixing ratio that produce the best match are 236 determined, the values of AOT and Ångström exponent are reported. For 237 dust-dominant cases, the values of single scattering albedo are retrieved in 238 addition to these parameters. MODIS Deep Blue data within MYD04_L2 239 includes AOT $(\tau)$ determination at $0.412,0.47,0.55$ and $0.66 \mu \mathrm{m}$, although 240 only the $0.412 \mu \mathrm{m}$ data are used here. MYD04_L2 data were obtained from 241 the Level 1 and Atmosphere Archive and Distribution System (LAADS; 242 http://ladsweb.nascom.nasa.gov/). The typical aerosol optical thickness for 243 visible light in clear air is 0.1 , very hazy skies have AOTs of $\geq 0.3$. During initial 244 processing, typical scale $(0.001)$ and offset $(0)$ values were applied to 245 MYD04_L2 AOT data prior to display and subsequent data processing.

\subsubsection{AURA OMI}

This paper focuses on an evaluation of MODIS data but for each case study, in addition to MODIS L1B and L2 aerosol data, co-incident data from

250 an independent sensor, the Ozone Monitoring Instrument (OMI) were also 251 acquired. OMI is on the Aura satellite (launch date: July 2004) which flies as 252 part of the NASA A-Train constellation (http://aqua.nasa.gov/doc/pubs/A253 Train_Fact_sheet.pdf) a few minutes behind the Aqua satellite. OMI is 254 designed to continue the Total Ozone Mapping Spectrometer (TOMS) record 255 for total ozone and other atmospheric parameters related to ozone chemistry 256 and climate. OMI measurements are sensitive to aerosol absorption in UV 257 wavelengths, thus providing an independent source of information relating to 258 mineral aerosol detection in the scene under observation. In addition, and 259 unlike MODIS, OMI AI (Absorbing Aerosol Index: e.g. Torres et al., 2007) is 260 sensitive to aerosol absorption even when the particles are above cloud and $261 \mathrm{AAl}$ is therefore derived successfully in both cloudless and cloudy conditions 262 (although see Ahn et al., 2008). OMI has a ground resolution of $13 \times 24 \mathrm{~km}$ Page | 8 
263 (nadir) and uses a retrieval algorithm similar to the one used by TOMS

264 (Torres et al., 1998). The OMI Al is defined as follows:

OMI AI = $100 \log _{10}\left(I_{360}{ }^{\text {Meas }} / I_{360}^{\text {Calc }}\right)$

where $\mathrm{I}_{360}{ }^{\text {Meas }}$ is the measured $360 \mathrm{~nm}$ OMI radiance and $\mathrm{I}_{360}{ }^{\text {Calc }}$ is the calculated $360 \mathrm{~nm}$ OMI radiance for a Rayleigh atmosphere. Under most conditions, the $\mathrm{Al}$ (Eq.1) is positive for absorbing aerosols and negative for non-absorbing aerosols (pure scattering). An Al $>1$ is typical of absorbing aerosols such as smoke or dust (Gassó \& Stein, 2007; Kubilay et al., 2005; Washington et al., 2003). In this instance, we have chosen to use the OMIAura_OMTO3E data, which is a daily Level 3 global gridded product which is generated by binning the original pixels from the Level 2 data products (15 orbits per day; $13 \times 24 \mathrm{~km}$ spatial resolution at nadir) into a $0.25 \times 0.25$ degree

278 global grid.

\subsection{Methods}

\subsubsection{Study region and event selection}

The performance of different MODIS dust detection methods in identifying source locations involved the analysis of four dust events which all originate in the same drainage basin. The Lake Eyre Basin (LEB), Australia was chosen for several reasons. First, it has been identified as a persistent and significant southern hemisphere dust source on the basis of surface observations (Middleton, 1986) and using TOMS Al (Washington et al., 2003).

289 Second, it is the only inland basin dust source region in Australia, a 290 geographically-isolated continent distant from other dust sources. 291 Consequently, within the LEB there is less potential for interaction with other 292 major dust sources than would be the case, for example, in the Sahara 293 (Prospero et al. 2002) or China (Shao \& Wang, 2003). Third, the basin is large 294 enough to give rise to several major dust events each year, but not such an 295 intense dust source as to make it difficult to discern individual plumes. 
The LEB covers 1.14 million $\mathrm{km}^{2}$, with mean annual rainfall of less than

$298125 \mathrm{~mm}$ and annual potential evaporation in excess of $2500 \mathrm{~mm}$. There are 299 several different sedimentary environments in the LEB, all of which emit dust.

300 The most significant of these are: (1) aeolian deposits covering $33 \%$ of the 301 basin area and accounting for $37 \%$ of the dust plumes, (2) alluvial deposits 302 and floodplains (11.55\% area, 30\% dust plumes), and (3) ephemeral lakes 303 and playas which cover only $2.26 \%$ of the basin area but from which originate $30429 \%$ of the dust plumes making these the most intense dust sources (figures 305 averaged over 2003-6: Bullard et al., 2008). Inter- and intra-annual variability 306 of dust storm frequency in the LEB is high, responding to changes in synoptic 307 pressure distributions across the continent (Ekstrom et al., 2004). The Sprigg 308 Model, which characterizes dust transporting wind systems in Australia 309 (Sprigg, 1982), suggests that as frontal systems pass over the LEB, pre310 frontal northerly and post-frontal southerly winds can entrain dusts which 311 travel southeast or northwest respectively. It is important to note, however, 312 that the estimated total annual number of dust events in the LEB varies not 313 only in response to climate but also as a result of differences in how events 314 are defined. In a previous study (Bullard et al., 2008), we examined MODIS 315 imagery for all days (between July 2003 and June 2006) where at least one 316 meteorological station in the LEB (or within $250 \mathrm{~km}$ of the catchment 317 boundary) recorded a dust-induced reduction in visibility to $\leq 1 \mathrm{~km}$ (which 318 corresponds to the WMO definition of a dust storm). Whilst there are some 319 inconsistencies in the relationship between visibility records from 320 meteorological stations and other indicators of dust emissions, (including 321 AERONET, TOMS Al and TOMS AOD: Mahowald et al., 2007) and the spatial 322 distribution of meteorological stations across the arid LEB is sparse which 323 means a number of events will be missed, visibility remains a useful criteria 324 for identifying days on which significant dust events have occurred. From the 32543 days on which dust events were identified four case studies were chosen 326 to illustrate key types of event that occur in the LEB, and also to include 327 factors which can significantly affect dust plume and source identification (i.e. 328 single /multiple dust plumes and varying amounts of cloud; see Figure 1; 329 Table 2). Although there are versions of some dust detection algorithms 330 designed to work at night (e.g. Wald et al., 1998), we focus on daytime events Page | 10 
331 here so that the influence of surface reflectance on dust source identification

332 can be explored.

$334<$ Insert Figure 1> -

$335<$ Insert Table 2>

\subsubsection{MODIS Level 1B Processing Algorithms}

As outlined earlier, mineral aerosol is sometimes detectable on unadjusted VIS satellite images (particularly over the ocean), but because

340 mineral aerosol can have similar reflectivity to the desert surfaces from which

341 it is entrained it can be difficult to detect over land. In addition, mineral aerosol

342 is often hard to differentiate from cloud, sea salt and anthropogenic pollution.

343 As a result of this, and also due to problems with the performance of MODIS

344 L2 aerosol products (section 2.1.1), a number of studies have used changes

345 in brightness temperature (TIR) to detect mineral aerosol over land surfaces.

346 Initial attempts using single TIR channel data, such as that by Shenk \& Curran

347 (1974) using Nimbus-THIR (Temperature Humidity Infrared Radiometer) 11

$348 \mu \mathrm{m}$ data, had limited success because changes in surface emissivity at this

349 wavelength can be misinterpreted as dust (Roskovensky \& Liou, 2003; 2005).

350 As a result of observed variability in the emissive and transmissive nature of

351 mineral aerosols within multiple TIR wavelength ranges, other researchers

352 have used methods based on brightness temperature difference (BTD) in

353 either two or three wavelength ranges, typically 11-12 $\mu \mathrm{m}$ bands (bi-spectral

354 split window technique) or near 8, 11 and $12 \mu \mathrm{m}$ bands (tri-spectral) (e.g.

355 Ackerman, 1997). BTD values from this method reveal temperature

356 differences that exist between the ground surface and cooler mineral aerosol

357 while at the same time are largely unaffected by absorption from other

358 atmospheric gases (Darmenov \& Sokolik, 2005). In addition to detecting dust

359 over land, these approaches may also allow discrimination between cloud and

360 dust when both exist in the vicinity of each other.

362 Here we initially apply the simple BTD approach detailed by Ackerman 363 (1997) to MODIS L1B data (Table 3). Using this methodology it has been 364 inferred that (BTD; 11.03-12.02 $\mu \mathrm{m}$ or MODIS $\mathrm{BT}_{31}-\mathrm{BT}_{32}$ ) values $<0 \mathrm{~K}$ signify Page | 11 
365 the presence of mineral aerosol (dimensionless) and BTD values $\geq 0 \mathrm{~K}$ 366 indicate no mineral aerosol. While developing the MODIS cloud mask, 367 Ackerman et al. (2002) have also placed the mineral aerosol detection 368 threshold at <-1 K. Although Ackerman's (1997) analysis implied that the $0 \mathrm{~K}$ 369 threshold could be widely used over a range of land surfaces, it is likely that 370 this will vary slightly according to variability in the emissive/transmissive 371 nature of the mineral aerosol. This in turn is determined by factors such as 372 mineralogy as well as processes acting upon the aerosol as it is transported in 373 the atmosphere. Mineralogical composition is an important control on the TIR 374 radiative properties of mineral aerosol and can vary significantly from region 375 to region (e.g. Claquin et al., 1999; Caquineau et al., 2002; Satheesh \& 376 Moorthy, 2005). Darmenov and Sokolik (2005) investigated the TIR radiative 377 signature of dust transported over oceans from 7 different regions and located 378 the BTD (11.03 -12.02 $\mu \mathrm{m})$ aerosol detection threshold at 0.5, -0.2, -1.0 and $3790.4 \mathrm{~K}$ for the Nubian, Thar, Gobi/Taklimakan and Australian deserts 380 respectively; but could not locate a clear threshold to distinguish mineral 381 aerosol from cloud for dust over oceans sourced from NW Africa, Libya or the 382 Iranian desert. It may also be the case that the threshold varies for a single 383 geographical region, the precise value being dependent on factors such as 384 the density of the dust plume (Darmenov and Sokolik, 2005) or local variation 385 in dust source mineralogy (e.g. iron-rich sources versus illite-rich sources). 386 This simple bi-spectral split window approach will be applied here to identify 387 appropriate aerosol detection thresholds over land for the Lake Eyre Basin.

Using BTD as a basis, a range of more complex algorithms has been 390 developed that combine BTD and VIS wavelengths to detect mineral aerosol 391 over land and remove the effects of dense cloud cover, which can obscure 392 dust, and cirrus clouds which have similar reflectance and BTD properties to 393 fine dust particles. In this paper we evaluate two of these cloud-removal 394 approaches applying them to MODIS L1B data for the LEB. The first is the 395 multispectral dust enhancement algorithm of Miller (2003) which exploits the 396 fact that dust particles can have contrasting VIS reflective properties when 397 compared to cloud (Table 3). In this model, an inverse brightness 398 temperature difference is used (BTD; 12.02-11.03 $\mu \mathrm{m}$ or MODIS $\mathrm{BT}_{32}-\mathrm{BT}_{31}$ ) Page | 12 
399 which is rescaled/normalized to lie within the -2 to $+2 \mathrm{~K}$ range. Based on 400 Miller's (2003) algorithm the mineral aerosol output (D) has values 401 constrained between 1.3 and 2.7 (dimensionless). In addition this approach, 402 through manipulation of the red $(R)$, green $(G)$ and blue $(B)$ display, enables 403 mineral aerosol to be visually differentiated from cloud using colour ( $D$ is 404 loaded on the red color gun). The second approach is that of Roskovensky 405 and Liou (2005) and Hansell et al., (2007) which focuses on the differentiation 406 of mineral aerosol from cirrus clouds by combining BTD $(11.03-12.02 \mu \mathrm{m})$ and 407 VIS wavelengths (reflectance ratio of $0.54 \mu \mathrm{m} / 0.86 \mu \mathrm{m}$ ). In the final output 408 image, values of $\mathrm{D}>1$ (dimensionless) indicate mineral aerosol is present and 409 values $\leq 1$ indicate cirrus cloud or non-mineral aerosol in the scene (Table 3). 410 Inclusion of the reflectance ratio in this case reduces the amount of false 411 detection of dust over land observed by Ackerman et al. (2002).

Although the majority of studies cited above have used data from 414 MODIS it is worth noting that similar approaches have been explored using 415 data from other sensors such as AVHRR, HIRS/2, GOES-8 and MSG-SEVIRI 416 with varying degrees of success (e.g. Legrand et al. 1989, Sokolik, 2002, 417 Schepanski et al., 2007).

$<$ Insert Table 3>

Table 3 includes a summary of the default threshold values used to 422 differentiate dust from non-dust in each of the original algorithms used here. 423 The threshold values used in these algorithms are sensitive to varying 424 atmospheric conditions, surface reflectance, dust density and dust 425 mineralogy, but are formulated in a manner such that they allow a certain 426 degree of tuning to adjust for specific conditions such as regional variability 427 (Darmonov \& Sokolik, 2005), or for dust blowing over land or ocean 428 (Roskovensky \& Liou (2005). In this study, we verified the published models 429 by using the authors' original data and study-events both to check the set up 430 of the algorithms and to ensure we could reproduce the initial values of 431 dust/non-dust threshold and coefficients used. For the four case studies 432 presented here, we therefore established event-specific thresholds using the Page | 13 
433 approach suggested by each author (Table 4). The definition of thresholds 434 therefore involved the interrogation of pixel histograms for each scene435 algorithm combination (see below). In each case, peaks were found to be 436 attributable to specific scene components (e.g. densities and types of cloud 437 and aerosol), and thresholds were chosen to represent the value which was 438 best able to identify dust in the scene, as judged by the user (Figure 2a). In 439 each case, peaks representing dust were relatively easy to identify and 440 disinter from other scene components, and the effects of the choice of dust 441 threshold in each case is outlined below. Given the rather inflexible nature of 442 this approach, data from other study regions, where atmospheric conditions 443 and water vapor concentrations vary more significantly, may pose a challenge 444 to the straightforward identification and threshold determination for dust peaks 445 outlined here.

446 Figure 2 shows the histograms used to derive BTD thresholds and 447 Miller's D for each event. For the Roskovensky and Liou (2005) output the 448 dust/non-dust threshold remained at 1, but the D-parameter scaling factor ' $a$ ' 449 and BTD offset ' $b$ ' were adjusted for each event by using the midpoints 450 between the clear sky and dust histograms of the reflectance ratio and BTD 451 respectively (Figure 3 ).

$453<$ Insert Figure 2>

$454<$ Insert Figure 3>

$455<$ Insert Table 4>

\subsubsection{Evaluation of output images}

458 To evaluate the different MODIS dust detection algorithms it is 459 necessary to have a common reference against which to compare the output 460 data. For each of the four dust events examined, an eight panel figure was 461 produced. In each case, panel (a) represents the MODIS VIS image (where 462 red $=$ band 1 , green $=$ band 4 , blue $=$ band 3 ). Panel $(b)$ represents the bi463 spectral brightness temperature difference $\left(B T D=B T_{31}-B_{32}\right.$ ) with no dust 464 threshold applied. This is the principal image against which the outputs from 465 the different algorithms outlined in panels (c) Ackerman (1997), (d) 466 Roskovensky \& Liou (2005) and (e) Miller (2003) were compared, because a Page | 14 
bi-spectral BTD is a common component of each of these Level 1B MODIS

468 algorithms. What is evaluated therefore is the extent to which the additional 469 components of the algorithms actually led to improved dust source detection. 470 In addition, a simple objective comparison of the outputs from each of the 471 Ackerman (1997), Roskovensky \& Liou (2005) and Miller (2003) algorithms is 472 shown in panel (f). To produce this, boolean outputs from panels (c), (d) and 473 (e), where pixels were categorized as dust $(=1)$ or non-dust $(=0)$ were colored 474 red, green and blue respectively and combined to create a color composite 475 output image. For example, if a pixel was categorized as dust following 476 Ackerman's (1997) procedure it will appear red; if categorized as dust by both 477 Ackerman (1997) and Miller (2003) it will appear pink; if all three algorithms 478 categorize it as dust it will appear white; if all three categorize it as non-dust it 479 will appear black (Figure 4).

$<$ Insert Figure 4>

Panels (g) and (h) represent the two dust products, MODIS L2 aerosol (MYD04) Deep Blue AOT and OMI Al respectively. Although the spatial resolution of the data is lower than the MODIS, OMI Al provides an independent check on the spatial extent and intensity of aerosol retrieval for all panels because it is not derived from MODIS.

Whilst a comparison of the different approaches to dust detection will help to understand how MODIS can best be used to identify the presence or absence of dust, the main aim of this paper is to evaluate the use of MODIS for identifying dust sources. This means that the way in which the upwind edge of the dust plume is depicted is of most interest. In these comparison figures, the areas highlighting the active sources for each event (denoted by coloured squares; e.g. figure 5), which were used to compare the outcome of 496 the techniques, were determined by an informed approach. Since the BTD 497 principle is a component of all of the evaluated algorithms (panels c-e), 498 sources were determined from a combination of the scene BTD plus other 499 readily available information, including the use of wind direction data to 500 ascertain the upwind side of plumes. From the companion dust source Page | 15 
501 inventory work of Bullard et al. (2008), certain sources in the LEB region could 502 be identified as relatively recurrent points of emission; locations which had a 503 record of acting as source areas for several different dust events across the 504 three year study period. The case study events here were therefore chosen to 505 ensure that several of the plume origins used for comparison were from 506 'proven' dust sources. Consequently, it is worth noting that the persistence of 507 certain key sources allowed their identification with a further confidence when 508 flagged as active in each BTD scene. One such example is the point-source 509 located at the south east margin of Lake Callabonna, South Australia (centred 510 on $140^{\circ} 15^{\prime} 0 \mathrm{E}, 30^{\circ} \mathrm{S}$.). This well-studied source location was seen to be active 511 in both the third and fourth case studies, where BTD data are able accurately 512 to indicate it as an area where a plume has originated (Figures 7 and 8). The 513 relative performance of the dust enhancement models was evaluated on this 514 basis. It is worth noting that extensive background knowledge of dust events 515 in the LEB was used to help verify source locations determined from BTD 516 data and this may not be possible in areas where comparable auxiliary data 517 are unavailable. Nevertheless, in this study, we were able to carefully and 518 thoroughly assess model performance for detection of dust emanating from 519 known source locations.

As noted earlier, there are some additional caveats to the use of remote sensing to determine (or infer) dust source locations; these include the relative timings of the satellite overpass and the onset of dust emissions 524 (which might affect not only the location of the plume head, but also the 525 density of the dust), and the fact that only the upwind dust source can be 526 located with any additional contributing sources lying under the dust plume 527 possibly going undetected. To test the likely impact of some of these issues, 528 HYSPLIT (http://www.arl.noaa.gov/ready) was used to calculate possible 529 trajectories and plume concentrations for each event. These data are not 530 presented here but confirm that the dust emitted during the events was close 531 to, or at, source at the time of data capture and rarely reached an altitude of 532 more than $500 \mathrm{~m}$. This suggests that overpass timings for remote sensing 533 data capture were likely to have provided data suitable for source 534 identification. 


\section{Results}

\subsection{Event 1: $7^{\text {th }}$ October 2005}

For this event, raised dust is quite difficult to observe in the visible scene (Figure 5a) and sources are not at all apparent regardless of the level of contrast enhancement applied. However, BTD analysis (Figure 5b) reveals the presence of dust plumes, which appear as dark streaks at the centre of the image. Much of the cloud in the lower left of Figure 5b also appears dark, indicating some overlap in the thermal signature of cloud and dust in this scene. This is further highlighted in Figure $5 \mathrm{c}$ where a dust/non-dust threshold of 0 (dust $<0$, cloud $>0$ ) has been applied. Here, not only are parts of the dust plumes categorized as dust, but so too are some of the patches of cloud. Although this simple threshold effectively separates cirrus cloud (white/light grey in Figure 5b) from the dust plumes, the thicker areas of cloud (which have similar BTD values to the dust) are mis-identified. Adjustment of the dust/non-dust threshold for this scene highlighted that there was no single BTD value that could differentiate these two components. In terms of identification of the sources of dust in this scene, there was an observed offset between the upwind dust heads shown in Figure $5 \mathrm{c}$ and the dust sources identified using Figure $5 \mathrm{~b}$. This is most likely to be because the dust at source is still close to the ground surface and therefore has a less pronounced thermal contrast with the ground surface than airborne dust further downwind of the source which will have risen to a higher atmospheric level. Given the dust/non-dust threshold applied to the scene is 0 , this also

561 indicates that some of the dust from this location can have a BTD value of $>0$

562 (Figure 5b).

$<$ Figure 5>

567 effectively removes the cirrus cloud from the scene, and only a small area of 568 the remaining cloud is included when a dust threshold (using event-specific ' $a$ ' Page | 17 
569 and 'b' coefficients; Table 4) is applied. The upwind ends of the main dust 570 plumes map on to the same source locations inferred from BTD (Figure 5b), 571 with the exception of the most northwestern plume which is not detected. 572 Miller's (2003) algorithm clearly differentiates the cloud from the main dust 573 plume (Figure 5e) which is picked out in red. With the exception of the 574 northernmost plume, source detection is comparable to those in Figure $5 \mathrm{~b}$. 575 However, there are some parts of this scene where dust is likely to have been 576 mis-identified. These areas (marked 'FS' in Figure 5e) are patches on the 577 ground surface where fires have changed the ground surface reflectance 578 characteristics significantly (Jacobberger-Jellison, 1994), and suggest that the 579 Miller algorithm is sensitive to ground reflectance variability. Given that the fire 580 scar is clearly discernible in the visible image (Figure 5a), but not when the 581 other techniques (which rely more heavily on BTD to detect dust) are used, 582 this implies that the component within the Miller (2003) algorithm that uses 583 VNIR wavelengths is slightly over weighted in this application. Figure $5 f$ 584 shows the extent to which the three MODIS L1B algorithms agree and 585 highlight co-incident pixels containing dust. Whilst all three pick out the main 586 central plumes of dust, there are considerable differences elsewhere in the 587 scene. In particular, the Miller (2003) algorithm suggests a much more 588 extensive plume of dust than the other two approaches, especially in the 589 northeast. All of the techniques misidentify some of the most dense cloud as 590 dust, with Ackerman (1997) and Miller (2003) performing particularly poorly.

The MODIS Deep Blue AOT image (Figure $5 \mathrm{~g}$ ) shows that the cloud 593 mask applied in this instance is effective in separating the clear or dusty sky 594 from the clouds, and some dust is detected (AOT values close to 0). The dust 595 plumes in the far right of the scene that are highlighted in previous panels 596 (Figure 5 b, c, and d) are clearly defined, but the main central plume is less 597 obvious. In comparison, despite the relatively coarse resolution, the $\mathrm{OMI} \mathrm{Al}$ 598 image (Figure 5h) depicts clearly the central and far right plumes, and with 599 similar Al values. This suggests that the inability of Deep Blue to detect both 600 of these plumes is not likely to be due to vastly different aerosol densities in 601 each plume. Instead, one possibility (explored further in section 4.6) is that 602 MODIS Deep Blue data are actually more sensitive to variations in dust colour Page | 18 
603 (mineralogy) than OMI. There is also an area in Figure $5 \mathrm{~g}$ that is excluded by 604 the Deep Blue cloud mask (marked 'FP' in Figure 5g) where cloud is not 605 apparent. On the ground, this is a floodplain and the high surface reflectance 606 characteristics also cause confusion for the cloud mask when applied to event 6073 (Figure $7 \mathrm{~g}$ ). Overall, the location of the dust plumes outlined by OMI Al data 608 correspond very closely to the position of the plumes in the MODIS 1B 609 algorithm outputs. In addition, the gridded Al data capture the extent and 610 variation of aerosol density apparent in the other panels. Although plume 611 identification is acceptable, the coarse resolution of the aggregated $\mathrm{OMI} \mathrm{Al}$ 612 data $\left(0.25^{\circ} \times 0.25^{\circ}\right)$ mean these data are less able to define the dust source 613 location or the nature of the surface sedimentary environments with the same 614 precision as can been achieved using the combination of outputs from the 615 MODIS L1B algorithms (e.g., Bullard et al., 2008; Lee et al., 2008).

\subsection{Event 2: $24^{\text {th }}$ September 2006}

In the second event, the downwind (northerly) limit of the advancing dust is very distinct in the MODIS VIS (Figure 6a). The upwind edges of the plume are, however, not distinct and are in places difficult to differentiate from the underlying bright desert surface. For Event 1, the dust/non-dust thresholds or coefficients chosen are the same as those recommended in the published techniques. However, if these values are applied to Event 2 some problems become evident. Figure 6 shows the visible MODIS (panel a) and BTD values (panel b) for Event 2 and the results of applying the Event 1 thresholds (Table 4; Figure 6 panels $\mathrm{c}-\mathrm{f}$ ). There is no possibility of identifying dust sources using the Roskovensky and Liou (2005) or Miller (2003) algorithms with these thresholds. The Roskovensky and Liou (2005) output suggests that the dust plume fills most of the panel, whilst no dust is

631 highlighted using the Miller (2003) approach. This is emphasized in Figure $6 f$ 632 which shows there are no areas of the image that all the different approaches 633 identify as containing dust. 
For this reason, thresholds and parameters appropriate to this event were determined using the histogram approach (see Table 4 for values). The results of applying these event-specific thresholds are shown in Figure 7 . The dust source areas for this event and extent of the plume are reasonably well discerned using BTD (Figure 7b), which also reveals several other minor plumes that are not evident in the VIS. When an event-specific threshold is applied to the BTD (Figure 7c) most of the plume is highlighted but some of the thin, discrete plumes are not identified as dust or are foreshortened. This again suggests the use of the dust/non-dust threshold can affect the accurate identification of dust sources. The main plume is successfully identified using Roskovensky and Liou's (2005) algorithm (Figure 7d) but the source areas are poorly represented. Despite extensive experimentation with the ' $a$ ' and 'b' coefficients to improve dust detection, it was not possible to pick out the westernmost dust plumes without introducing a significant component of the ground surface reflectivity to the dust determination.

$<$ Figure $7>$

Using Miller's (2003) algorithm (Figure 7e), the maximum D value for this event falls below the published dust $>1.3$ threshold (see Table 3 ) necessitating an adjustment of this threshold such that dust $>-0.55$. Although this adjustment enhances the dust visualization significantly, it does not do so without introducing further artifacts. First, some areas of the plume evident in 660 Figure $7 \mathrm{~b}$ were not highlighted, for example the thin streaks to the left of the 661 main plume that were also not identified using the default Ackerman (1997) or 662 Roskovensky and Liou (2005) thresholds (Figures 7c and d). Second, whilst 663 detection of airborne dust is improved, some areas of the ground surface are 664 also mis-identified as dust. Some of these are the same areas (marked FS in 665 Figure 7e) that caused difficulties in event 1 due to changes in surface 666 reflectivity caused by fire scars, and can clearly be seen in other panels 667 (Figure 7 a-d).

Figure $7 f$ shows that the agreement between the MODIS L1B 670 enhancement methods for dust (white) is restricted to the most dense part of Page | 20 
671 the plume. Ackerman (1997) performs best at highlighting the more subtle 672 (perhaps less dense) dust plumes in the west of the scene. The Roskovensky 673 and Liou (2005) threshold mis-identifies dust not only to the west but also to 674 the south and so under-represents its spatial extent; with obvious implications 675 for upwind source detection.

The central dust plume is shown clearly in the MODIS Deep Blue aerosol product for this event (Figure 7g). Not only is the sharp advancing dust front apparent, but these data also indicate higher dust concentrations in the southerly, upwind source area of the plume. At best, however, these data are only able to provide a broad regional indication of the plume's source because the thin, discrete plumes in the west are not detected. The MODIS Deep Blue product also suggests that the highest AOT values in the scene are associated with the plume at the extreme eastern edge of the scene (marked ' $X$ '). This contrasts with the MODIS BTD analyses where dust appears to have a higher concentration at the furthest downwind edge of the plume (marked ' $Y$ '). Similarly, OMI Al data clearly outline the main plume, and also suggest higher aerosol density in the east (Figure 7h). Comparison of the Deep Blue and OMI data highlight the performance of the cloud masks used in these products. The Deep Blue cloud mask only removes the cloud in the top left of the scene, which is clearly present in MODIS VIS, whilst the OMI cloud-mask obscures as much as $15 \%$ of the scene.

\subsection{Event 3: $2^{\text {nd }}$ February 2005}

Event 3 was an extensive dust event during which 35 meteorological stations recorded a reduction in visibility to $\leq 1 \mathrm{~km}$. Here we concentrate on two areas in the central LEB: the first is where two parallel dust plumes can clearly be seen blowing northwards out of Lake Eyre North and the second is in the lower right corner of the image and is difficult to see in the VIS (Figure

$7018 \mathrm{a}$ ), but is clearly shown on the BTD (Figure 8b). The previous two events 702 used a BTD threshold of $<0$ with varying success. For this event (Figure $8 \mathrm{c}$ ), a 703 significantly lower threshold for dust detection (dust <-1.2) was required to 704 identify dust plumes (Table 4). Using this value, most of the pixels highlighted Page | 21 
contain dust although the area marked 'GS' on Figure $8 \mathrm{c}$ is not dust, but is the ground surface. Crucially, the $<-1.2$ threshold in this instance does allow the observed dust plumes to be traced all the way back to the source areas.

$<$ Figure 8>

The Roskovensky and Liou (2005) algorithm (Figure 8d) is effective at picking out the two main dust areas, but the origin of the twin plumes is situated north of the known dust source (the bed of Lake Eyre North). The parallel plumes are also visible when Miller's (2003) algorithm (Figure 8e) is applied with an adjusted dust threshold, but this dense dust is only enhanced by the model (coloured red) at the downwind end of the plume, and not in the source locations. Furthermore, in comparison to BTD (Figure 8b), the origin of the dust in Figure $8 \mathrm{e}$ (in white) would be placed approximately $70 \mathrm{~km}$ north of the actual lake bed source. The 'best' dust threshold that could be determined for the Miller (2003) algorithm in this instance also seems to divorce the apparent upwind boundary of the plume from the source area marked ' $X$ ' in the right of the image (Figure $8 \mathrm{e}$ ). However, the entire aerosol outbreak to the lower right is highlighted in red using this approach, and the plume clearly extends back to the assumed source. This demonstrates that there can be significant variability in the performance of this enhancement approach within a single scene. The composite image (Figure 8f) for the MODIS L1B enhancement techniques highlights the problem of surface reflectance evident when applying the Miller algorithm, as to the northwest of the twin plumes the fire scar (FS) is clearly shown in blue.

In Figure 8g, the distinctive parallel dust plumes are mainly excluded by the Deep Blue cloud mask, and only the downwind end of the plume is detected. Other parts of the image, where no cloud is present (cf. Figure 8a), are also excluded by the cloud mask. For example, the dry bed of Lake Eyre and small patches across the whole area of the scene are flagged as no-data. In Figure 8h, the OMI Al data show dust over the majority of the scene, suggesting a widespread dust haze. The Al maximum of 5.4 is very high for Australia but, whilst all the main areas of dust are identified in a manner Page | 22 
broadly consistent with the MODIS L1B algorithms, the spatial resolution is insufficient to illustrate the detail of the parallel plumes or the specific source locations. Indeed, although these data clearly have limited utility for determining the specific point-sources in this scene, the OMI data do suggest the presence of diffuse raised dust across the scene which would be expected given the number of meteorological stations recording the event.

\subsection{Event 4: 30th August 2005}

The weather systems that promote LEB dust storms (thunderstorms, pre- and post-frontal winds; Sprigg, 1982) mean that dust events are often associated with cloud cover. Event 4 was selected to explore further the extent to which dust and cloud can be distinguished. Dust is visible in the centre of the VIS scene between the bands of cloud (Figure 9a) and can also be identified using BTD (Figure 9b); although large areas of thicker cloud can be seen which exhibit a similar BTD as the dust, making initial interpretation of this scene using BTD alone problematic. A dust threshold of $<-0.35$ was applied to BTD in this instance (Figure 9c), and was effective in isolating the major dust plumes that exist between the clouds, but at the expense of the thinner plumes which are removed when this particular threshold is applied.

$<$ Figure 9>

Most of the cloud is removed from the image by application of Roskovensky and Liou's (2005) algorithm (Figure 9d) and the inferred sources for the two main dust plumes clearly map on to those identified from BTD (Figure 9b). For this event, the Miller (2003) algorithm (Figure 9e) was scaled using dust $>0.45$, and can be seen to be very effective as the principal dust plumes are easily discernable and source determination is possible. The enhancements discussed here are unable to ameliorate the blanketing effect of thick cloud when it obscures active dust sources or plumes; they can only enhance the dust that can be 'seen' between the cloud banks. Interestingly, none of the BTD-based methods pick up the thin plume which is best seen on the MODIS visible panel (marked ' $X$ ', Figure 9a). The most notable feature, Page | 23 
other than the general agreement of spatial extent and source location for the two plumes shown in Figure 9h, is the appearance of the blue areas where the Miller (2003) output has confused the thickest cloud with dust.

The cloud masking of the Deep Blue (Figure 9g) scene seems to work well for much of the cloud coverage in the image, but does also remove much of the northernmost dust evident in the other panels (Figures 9b-f). The shape and downwind extent of the central plume is indicated by raised AOT values, but the MODIS Deep Blue data also suggest an origin for the dust that is some distance removed downwind from the source when compared with the BTD-based approaches. The OMI data (Figure 9h) again show more of the dust plume than the MODIS Deep Blue product, and less of the image is affected by cloud masking.

\section{Discussion}

The main aim of this paper is to evaluate the use of MODIS for detecting dust sources. In some instances dust plumes may be discernible on the MODIS VIS (e.g. Figure 6); but this certainly is not always the case (e.g. Figure 4). From the results presented above, we can confirm that all the dust enhancement techniques used here make it easier to detect dust. However, with respect to source determination, the results suggest that, of the MODIS L1 processing techniques, the 'best' approach varies from event to event. For events 1 and 2 arguably the best source detection came from the simple brightness temperature difference calculation (BTD), often with no dust threshold applied. Of the more complex processing techniques, that of Roskovensky \& Liou (2005) works well for event 1 (Figure 5) as it is very effective at removing cloud cover, whereas the Ackerman (1997) is better for events 2 and 3, where cloud cover is less of an issue. The cloud cover in event 4 (Figure 8) makes it much harder to determine sources from the BTD alone, but both Roskovensky \& Liou (2005) and Ackerman (1997) work well. For these four events, the Miller (2003) algorithm is extremely useful for visualizing dust, but there are significant problems with precise source identification and determination of dust plume extent in all cases except event 
807 4. For the majority of events and algorithms the published, or indicative, 808 thresholds under-perform and the values vary from event to event. This

809 makes it difficult to suggest appropriate regional scale thresholds. Whilst 810 some of this variation is due to factors specific to the algorithms or individual 811 events, other causes such as diurnal and seasonal variations in surface 812 temperature/dust contrast (which affect BTD) will affect all the methods. The 813 advantages and disadvantages of each of the approaches from an operational 814 perspective are discussed in detail below.

\subsection{Brightness Temperature Difference (bispectral split window)}

Calculating BTD is straightforward, and keeping the full range of values (rather than applying a dust threshold) is often preferable for both dust plume and source detection. The procedure does not appear to be very sensitive to observed mineralogical variability either within or between plumes, and so all dust, regardless of source, is enhanced provided it can be differentiated thermally from the ground surface. The main disadvantages are that because no definition of dust/non-dust is applied the interpretation of the BTD data becomes subjective and data retrieval can suffer through lack of cloud cover elimination. With the exception of event 4 , this is not a major problem in the case studies presented here, but it is likely to be important for anyone interpreting the data, to have a good understanding of how and why ground

\subsection{Ackerman (1997)}

Although Ackerman (1997) did not explicitly present a dust/non-dust 834 threshold of zero, he observed negative differences in $B T_{11}-\mathrm{BT}_{12}$ for dust 835 storms and a universal threshold of dust $<0$ could be implied. Darmenov \& 836 Sokolik (2005) demonstrated that this dust threshold was in fact variable when 837 applied to dust over oceans and suggested that dust sourced from the Lake 838 Eyre Basin and travelling southeast over the Tasman Sea had a value of <$8390.4 \mathrm{~K}$. All the dust plumes examined here are over land, and whilst the 840 threshold of zero worked effectively for events 1 and 2, adjustments had to be Page | 25 
841 made for events 3 and 4 . For event 3 , in order to eliminate interference from

842 the ground surface, the threshold had to be lowered to $<-1.2 \mathrm{~K}$; for event 4 the

843 threshold was $<-0.35$ to eliminate cloud. Interestingly, whilst it was possible to

844 find a dust/non-dust threshold for event 4 where all cloud could be removed

845 this was not possible for event 1 . Here (Figure 5c), a dust threshold lower

846 than zero removed more dust in the scene so the threshold was left at 0.

847 Another factor affecting the BTD threshold is likely to be the thickness of the

848 dust plume. Where there is low AOT (as confirmed by comparison with

849 MODIS Deep Blue) we have determined BTD differences of $>0$ for pixels

850 populated by dust. One possibility is that where the dust plume

851 thickness/density is low, BTD becomes increasing affected by the ground

852 surface temperature signal. Using this approach, therefore, may involve a

853 compromise between dust detection and the elimination of cloud. If both dust

854 and cloud are dense/opaque then it is straightforward to identify and

855 implement a dust threshold. If the dust is thin and cloud cover is dense (as in

856 event 1), then it can be hard to identify an appropriate dust/non-dust

857 threshold. Where the cloud cover is sparse and the dust plume is

858 dense/opaque (as in event 4) then their differentiation through threshold

859 adjustment is straightforward. From this study it is also apparent that the

860 thickness/density of the dust plume also affects the degree to which the dust-

861 head can be pinpointed, and an inappropriate threshold value may

862 foreshorten plumes.

863

$864 \quad 4.3$ Roskovensky \& Liou (2005)

865

866

867 differentiation of dust from cirrus cloud, and is very effective at doing so in 868 both of the cloudy scenes examined here (events 1 and 4). For all events it 869 was necessary to adjust the scaling factor ' $a$ ' and BTD offset value ' $b$ '.

870 Roskovensky and Liou (2005) calculated these to be 1.1 and 0 over ocean

871 (around the Korean peninsula) and 3 and 0 over land (the Gobi desert). All of

872 the events examined here occurred over land and the coefficients determined

873 were variable (values of ' $a$ ' ranged from 0.25 to 1.2 and values of ' $b$ ' ranged

874 from -0.5 to +1 ) and made a significant difference to both the number of Page | 26 
875 pixels classified as dust and the inferred location of the dust sources.

876 Although the algorithm is slightly more computationally complex to calculate 877 than simple BTD, it is easy to tune it for specific events, and certainly worth 878 the extra effort. Overall this model worked best on dense dust; there was little 879 observed confusion with ground surface reflectance, and the inferred upwind 880 plume source locations compared well with those suggested by BTD alone.

881

$882 \quad 4.4 \quad$ Miller (2003)

The Miller (2003) algorithm is designed to provide improved 885 differentiation of dust from water/ice clouds over bright desert surfaces and was found to be visually very effective for all events observed in this study. In particular, there is generally a clear distinction between dust and cloud. In a similar manner to optimizing the Ackerman (1997) data, the Miller (2003) dust threshold also had to be tuned for each event to be effective (Table 4) and in most cases it was necessary to decrease the lower threshold value to well below Miller's suggested +1.3 (as low as -0.55 in one instance). Unfortunately tuning this algorithm was not straightforward, and although it worked very well for some events, this was not always the case.

\subsection{The Aerosol Products (Deep Blue and OMI)}

The main utility of the aerosol products is in the detection of dust because for dust source identification the coarse spatial resolution of the products is a limitation. Average Al values over a long time series have been used to detect persistent, regional scale dust sources (e.g. Washington et al., 2003) but accurate and event-specific source identification requires the clear delineation of the upwind margin of the plumes. We have presented values of Deep Blue AOT and OMI Al which, whilst not comparable in terms of absolute values can be compared relatively. There are occasions where OMI agrees well with the much higher resolution MODIS, but often the upwind margin of a dust plume is difficult to detect using $\mathrm{Al}$. 
In some cases, it was difficult to determine not only the upwind dust sources but also the extent of the dust plumes because the in-built cloud masks of the products eliminated them. For example, in Figure $8 \mathrm{~g}$, the origin

911 of the parallel twin plumes was not discernible because MYD04 returned no

912 data from the bright dry lake surface, which was classified as cloud. This is a

913 recognised limitation and is probably due to the colour and density of the dust

914 or reflectance of the surface. The twin parallel plumes comprise white

915 coloured dense dust sourced from Lake Eyre and are sufficiently bright to

916 saturate the pixels causing misidentification as cloud (a known problem with

917 Level 2 aerosol product http://modis-

918 atmos.gsfc.nasa.gov/MOD04_L2/ga.htm). There are obvious implications for

919 dust source identification - ephemeral lakes are often very bright surfaces

920 and have been seen in this study to be routinely masked out as cloud even in 921 cloud-free and dust-free scenes, yet are common dust sources not only in the 922 LEB (Bullard et al. 2008), but also in the USA (e.g. Reynolds et al. 2007), 923 southern Africa (Mahowald et al. 2003) and other dryland regions. The 924 authors are also evaluating the Aura-OMI Aerosol Data Product; OMAERUV 925 (V003) which provides aerosol extinction and optical depth via swath data 926 (rather than global gridded) at the native $13 \times 24 \mathrm{~km}$ pixel (see:

927 http://daac.gsfc.nasa.gov/Aura/OMI/omaeruv.shtml). This may offer further 928 potential for dust source identification, but requires further validation.

\subsection{Impacts of Dust Mineralogy and Surface Reflectance on Data Retrieval}

One issue that can be explored briefly here, and will be developed

933 further as a future project, is the impact of dust mineralogy on both the Miller 934 (2003) dust thresholds and MODIS Deep Blue retrievals. A range of different 935 sedimentary environments emit dust within the Lake Eyre Basin (Bullard et al., 936 2008) and these have different mineralogical compositions which in turn 937 control the infrared radiative properties of the dust (Claquin et al., 1999; 938 Sokolik, 2002). An example can be seen in event 3 (Figure 8) where a dust 939 plume was observed originating from the bed of Lake Eyre (which is illite-rich), 940 in the west of the scene and a dust plume originating from dune sands with 941 iron-rich coatings in the southeast of the scene. Using threshold values Page | 28 
942 where $0.6<$ dust $<1.98$ it was possible to pick out the dust sourced from the

943 dunes in red, but not the near-source dust from the lake (although part of the

944 distal end of the plume is highlighted). When a threshold was selected to

945 highlight both plumes large areas of ground surface were also included.

The effect of dust mineralogy on detection is also apparent in the 948 MYD04 Deep Blue data presented here. In the Deep Blue algorithm, surface 949 reflectivity over desert regions is assumed to be low in blue wavelengths and, 950 dust aerosol slightly more reflective (Hsu et al., 2004). However, dust 951 reflectivity is variable depending on its chemistry and can decrease 952 significantly with increased iron concentration (Dubovic et al., 2002; Arimoto 953 et al., 2002). Consequently red, or iron-rich, dust will have relatively low blue 954 reflectivity and therefore potentially lower contrast relative to background 955 reflectance, whereas white dust (composed of carbonates, bleached quartz or 956 evaporite minerals) will have higher reflectance in the VIS and significantly 957 higher contrast with respect to underlying soils and vegetation. This is 958 illustrated in Figures $7 \mathrm{~g}$ and $8 \mathrm{~g}$ where the white, dry lake bed sources of dust 959 are more distinct than the iron-oxide rich dust from dune sources (noting 960 however that the OMI product suggests these red plumes are also less dense 961 than the white dust plumes which will affect AOT).

For the Lake Eyre Basin events there are some problems with the differentiation of dust from the underlying desert surface. Specifically, large areas of the LEB dunefields comprise red brown to orange, highly reflective sands with a partial vegetation cover; although sand color is variable especially between the redder Simpson dunefield and the less red Strzelecki dunefield (Pell et al., 2000; Bullard and White, 2002). Where the vegetation cover has not been disturbed by fire, the Miller (2003) algorithm works well.

970 However, where vegetation has been removed by fire and large areas of 971 bright sand are exposed the algorithm cannot distinguish dust from the 972 surface. Fire changes both surface reflectance characteristics, through the 973 removal of absorbing vegetation, and sediment reflectance characteristics, 974 through fire-induced reddening or changes in mineralogy (Jacobberger975 Jellison, 1994). The way in which the performance of the Miller (2003) Page | 29 
976 algorithm is affected by these changes has important implications for dust 977 provenance because areas which have been de-vegetated through fire may 978 be mis-identified as a dust source. A complicating issue is that fire scars can 979 act as sources of dust under certain conditions (Bullard et al. 2008; McGowan 980 \& Clark, 2008). This highlights two issues. First, it is important to deploy 981 event-specific dust/non-dust thresholds to limit the influence of surface 982 reflectance as far as possible. Second, familiarity with the underlying surface 983 characteristics is essential, and examination of more than one scene, 984 including known dust-free images is desirable. The latter means that 985 permanent or semi-permanent ground characteristics can be discerned. For 986 example, the firescars in the LEB have distinctive shapes that can be 987 identified on most of the VIS images taken post-2001 when widespread 988 burning occurred. Cross-referencing with other MODIS-derived output can 989 also be useful. For example, in event 1 the fire scar is only clearly discernible 990 on the VIS and Miller (2003) panels which suggests that it was not a dust 991 source. In contrast, in event 2 the fire scars are discernable in all panels 992 (Figure 7 a-e) which may suggest that they acted as dust sources at this time.

\subsection{Tools for dust source detection}

Figure 10 presents a summary of the how the different data sources and analyses used here complement one another. At the global-regional scale, dust events can be detected using visibility criteria, as in this paper, or OMI Al. An alternative that we have not discussed in detail here is the MOD/MYD08 Global Gridded Atmospheric Product (1 x $1 \mathrm{deg}$ ) which could also be used (Bryant et al., 2007), although it has some limitations over bright desert surfaces (Chu et al., 2002). If none of these three indicates dust it does not necessarily mean that dust is not present as the relative timing of satellite overpass or visibility observation may result in no dust being recorded (see quality control indicators), but the events missed are likely to be minor. If any one of these indicates the presence of dust then there is the potential for

1007 determining dust sources at higher resolution. The choice of higher resolution 1008 technique depends on the precise research question to be answered. The

1009 MOD/MYD04 aerosol products give data processed to a common standard Page | 30 
1010

1011

1012

1013

1014

1015

1016

1017

1018

1019

1020

1021

1022

1023

1024

1025

1026

1027

1028

1029

1030

1031

1032

1033

1034

1035

1036

1037

1038

1039

1040

1041

1042

1043

that enables comparison from one region to another. The versatile MOD/MYD02 data can be processed simply using brightness temperature difference to enhance the dust signal. Where cloud is present, or if it is necessary to highlight the dust plume then one of the methods for employing a dust/non-dust threshold can be used, but it is recommended that eventspecific thresholds are calculated where possible (as opposed to using global or regional thresholds).

\section{Conclusions}

This paper set out to evaluate the use of MODIS data for identifying dust sources. Through objective and subjective comparison of several different approaches to dust detection several conclusions can be drawn. Whilst these conclusions have implications for regional and global scale studies of dust, the clear outcomes are that even within a single drainage basin, dust events should be examined on an event by event basis, and that the 'best' algorithm for identifying dust sources varies considerably.

(1) For the region examined here (the Lake Eyre Basin), no single MODIS technique was found to be ideal for source determination.

(2) MODIS VIS full colour composite data can be useful but are often insufficient to discern dust plumes over reflective desert surfaces. In particular, for event detection MODIS VIS (particularly via quicklooks) should be used with caution, or in combination with other data sources, because not all dust plumes will be visible over the bright surfaces. An ideal combination for rapid detection of dust activity is OMI Al (or equivalents) and MODIS but the former can not be used to derive source location due to its low spatial resolution.

(3) BTD data are simple to calculate and very effective at highlighting dust that is not seen in VIS data. If the user is familiar with the underlying ground surface characteristics and has the VIS image available to discern cloud cover, this can be the most simple and possibly most accurate method of source determination. From the four example events presented here, BTD is the approach that is least sensitive to dust mineralogy. 
(4) For scenes where cloud is present, there is potential for confusion between cloud and dust using just BTD and the algorithms designed to differentiate these have been demonstrated as effective for screening out cirrus cloud (for which they were designed) although thick cloud can remain.

(5) Whilst there are published dust/non-dust thresholds for each method compared here, for each method thresholds may need adjusting on a regional and/or event scale. Although there are clear guidelines for positioning thresholds, a considerably amount of informed (but subjective) judgement can be required. It is important therefore for users of these techniques to consider the effects of not adjusting thresholds for each event. This paper suggests that for an eventbased study it is essential to derive event-specific thresholds. However it seems likely that for global or longer-term studies of this nature to be effective, it may be pragmatic to use regional thresholds.

(6) In the Lake Eyre Basin, it is not possible to use a single dust/non-dust threshold for all events for any of the algorithms tested here. One possible reason is that it is a basin with multiple potential dust sources with different mineralogies; where different sources (e.g. iron-rich dunes, illite-rich lake beds) can emit dust simultaneously it is necessary to use event-specific, or even plume-specific thresholds. In regions with a single definable source (for example a large playa such as the Magkadigadki, Botswana) it may be possible to discern a single dust/non-dust threshold, however any use of a regional (or global) threshold is likely to result in errors or inconsistencies.

(7) Some sedimentary environments are more intense dust sources than others. In particular, previous studies have noted ephemeral lakes and areas devegetated by fire as prominent dust sources. Significantly, these are two of the ground surface types that have proved most problematic for establishing dust/non-dust thresholds due to confusion caused by their bright surfaces which cause false positive dust signals or may be falsely identified as cloud.

(8) Whilst the findings of this research may be challenging in some respects, what is clear is that there is considerable potential for using 
MODIS data to obtain information about dust mineralogy by interpreting the shifts to the thresholds (or coefficients) that need to be made. Possible mineral aerosol information that could be gained can not only assist in identifying the dust source, but also its radiative properties.

Using data from sensors such as MODIS will inevitably mean that some dust activity is missed due to the relative timing of overpass and dust emissions or cloud cover. Other sources of data such as MSG can minimize the problem of overpass timings but cloud cover is still a problem and coverage is not yet global. This paper has focused on daytime dust emissions only, but analysis of night time dust emissions and source identification are the subject of future research. It is worth noting that the products and data used here are subject to continual development and improvement and consequently some of the issues raised here may be resolved or change. 


\section{Acknowledgements}

1096 This research was part of a project funded by The Leverhulme Trust, (JEB),

1097 for which MCB was the post-doctoral research fellow. The authors would like

1098 to thank Steve Miller, Clare Salustro and Christina Hsu for their technical

1099 assistance and useful discussions. The highly valuable comments of three

1100 anonymous reviewers also helped to improve this paper. 
Ackerman, S.A. (1997). Remote sensing aerosols using satellite infrared observations, Journal of Geophysical Research, 102, 17069-17080

Ackerman, S.A., Strabala, K.I., Menzel, W.P., Frey, R., Moeller, C., Gumley, L., Baum, B.A., Seeman, S.W., \& Zhang, H. (2002). Discriminating clearsky from cloud with MODIS algorithm theoretical basis document (MOD35). In ATBD Ref.ATBD-MOD-06, version 4.0, 115 pp. Greenbelt, Maryland: NASA Goddard Space Flight Center

Ahn, C., Torres, O., \& Bhartia, P.K. (2008). Comparison of ozone monitoring intrument UV aerosol products with Aqua/Moderate Resolution Imaging Spectroradiometer and Multiangle Imaging Spectroradiometer observations in 2006. Journal of Geophysical Research, 113, D16S27

Agarwal, A., El-Askary, J.M., El-Ghazawi, T., Kafatos, M. and Le-Moigne, J. (2007). Hierarchical PCA techniques for fusing spatial and spectral observations with application to MISR and monitoring dust storms. IEEE Geoscience and Remote Sensing Letters, 4, 4, 678-682.

Alpert, P., Kishcha, P., Shtivelman, A., Krichak, S.O. \& Joseph, J.H. (2004). Vertical distribution of Saharan dust based on 2.5-year model predictions. Atmospheric Research, 70, 109-130.

Arimoto, R., Balsam, W., Schloesslin, C. 2002. Visible spectroscopy of aerosol particles collected on filters: iron-oxide minerals. Atmospheric Environment, 36, 89-96.

Badarinath, K.V.S., Kumar Kharol, S., Kaskaoutis, D.G. \& Kambezidis, H.D. (2007). Dust storm over Indian region and its impact on the ground reaching solar radiation - a case study using multi-satellite data and ground measurements. Science of the Total Environment, 384, 316332.

Brindley, H. E., \& Ignatiov, A. (2006). Retrieval of mineral aerosol optical depth and size information from Meteosat Second Generation SEVIRI solar reflectance bands. Remote Sensing of Environment, 102, 344-363, doi:10.1016/j.rse.2006.02.024

Bryant, R. G., Bigg, G. R., Mahowald, N. M., Eckardt, F. D., \& Ross, S. G., (2007). Dust emission response to climate in southern Africa. Journal of 
Bullard, J. E., Baddock, M. C., McTainsh, G. H., \& Leys, J. F., (2008). Subbasin scale dust source geomorphology detected using MODIS. Geophysical Research Letters 35, 1, art.no.L15404, doi:2008GL033928.

Bullard, J. E., \& White, K. H., (2002). Quantifying iron oxide coatings on dune sands using spectrometric measurements: an example from the

Caquineau, S., Gaudichet, A., Gomes, L., \& Legrand, M. (2002). Mineralogy

de Baar, H.J.W. and 33 others (2005). Synthesis of iron fertilization of Saharan dust transported over northwestern tropical Atlantic Ocean in relation to source regions. Journal of Geophysical Research, 107(D15), 4251, doi:10.1029/2000JD000247

Chu, D.A., Kaufman, Y.J., Ichoku, C., Remer, L.A., Tanré, D. \& Holben, B.N. (2002). Validation of MODIS aerosol optical depth retrieval over land. Geophysical Research Letters, 29, 12, 8007, doi:10.1029/2001GL013205.

Claquin, T., Schulz, M., \& Balkanski, Y.J. (1999). Modeling the mineralogy of atmospheric dust sources. Journal of Geophysical Research, 104, 22243-22256

Darmenov, A. \& I.N. Sokolik (2005). Identifying the regional thermal-IR radiative signature of mineral dust with MODIS. Geophysical Research Letters, 32, L16803, doi:10.1029/2005GL023092 experiments: from the iron age in the age of enlightenment. Journal of Geophysical Research-Oceans, 110, C9, C09S16.

Desboeufs, K.V., Sofikitis, A., Losno, R., Colin, J.L., \& Ausset, P. (2005). Dissolution and solubility of trace metals from natural and anthropogenic particulate matter. Chemosphere, 58, 2, 195-203.

Dubovik, O., Holben, B., Eck, T.F., Snirnov, A., Kaufman, Y.J., King, M.D., Tanré, D. \& Slutsker, I. 2002. Variability of absorption and optical properties of key aerosol types observed in worldwide locations.

1168 Dubovik, O., Lapyonok, T., Kaufman, Y.J., Chin, M., Ginoux, P., Kahn, R.A. \& Page | 36 
Sinyuk, A. (2008). Retrieving global aerosol sources from satellites using inverse modeling. Atmospheric Chemistry and Physics, 8, 2, 209-250.

Eckardt, F.D., \& Kuring, N. (2005). SeaWIFS identified dust sources in the Namib Desert. International Journal of Remote Sensing, 26, 19, 41594167

Ekstrom, M., McTainsh, G.H., \& Chappell, A. (2004). Australian dust storms: temporal trends and relationships with synoptic pressure distributions (1960-1999). International Journal of Climatology, 24, 12, 1581-1599.

Erickson, D.J., Hernandez, J.L., Ginoux, P., Gregg, W.W., McClain, C., \& Christian, J. (2003). Atmospheric iron delivery and surface ocean biological activity in the Southern Ocean and Patagonian region. Geophysical Research Letters, 30, 12, doi:10.1029/2003GL017241

Evan, A. T., A. K. Heidinger, and M. J. Pavolonis (2006) Development of a new over water Advanced Very High Resolution Radiometer dust detection algorithm. International Journal of Remote Sensing, 27(18), pp. 3903-3924. doi: 10.1080/01431160600646359

Gassó, S. \& A.F. Stein (2007). Does dust from Patagonia reach the subAntarctic Atlantic Ocean. Geophysical Research Letters, 34, L01801, doi:10.1029/2006GL027693

Hansell, R.S., Ou, S.C., Liou, K.N., Roskovensky, J.K., Tsay, S.C., Hsu, C., \& Ji, Q. (2007). Simultaneous detection/separation of mineral dust and cirrus clouds using MODIS thermal infrared window data. Geophysical Research Letters, 34, L11808, doi:10.1029/2007GL029388

Haywood, J., \& Boucher, O. (2000). Estimates of the direct and indirect radiative forcing due to tropospheric aerosols: a review. Reviews of Geophysics, 38, 4, 513-543.

Hsu, N.C., Herman, J. R. \& Weaver, C. (2000). Determination of radiative forcing of Saharan dust using combined TOMS and ERBE data. Journal of Geophysical Research, 105, 20649-20661

Hsu, N. C., Tsay, S. C.King, M. D. \& Herman J. R. (2004). Aerosol properties over bright-reflecting source regions, IEEE Transactions on Geoscience and Remote Sensing, 42, 557-569

Hsu, N.C., Tsay, S-C, King, M.D., \& Herman, J.R. (2006). Deep Blue retrievals 

of Asian aerosol properties during ACE-Asia. IEEE Transactions on Geoscience and Remote Sensing. 44, 11, 3180-3195. doi:10.1109/TGRS.2006.879540

Jacobberger-Jellison, P.A. (1994). Fire-induced reddening of dune sands. Journal of Arid Environments, 26, 305-313.

Jickells, T.D. and 18 others, (2005). Global iron connections between desert dust, ocean biogeochemistry and climate. Science, 308, 67-71

Jones, T.A. \& Christopher, S.A. (2007). MODIS-derived fine mode fraction characteristics of marine dust and anthropogenic aerosols over the ocean constrained by GOCART, MOPITT and TOMS. Journal of Geophysical Research - Atmospheres, 112, D22, D22204.

Jones, T.A. \& Christopher, S.A. (2008). Multispectral analysis of aerosols over oceans using principal components. IEEE Transactions on Geoscience and Remote Sensing, 46, 9, 2659-2665.

Kaskaoutis, D.G., Kambezidis, H.D., Nastos, P.T. \& Kosmopoulos, P.G. (2008). Study on an intense dust storm over Greece. Atmospheric Environment, 42, 9, 6884-6896.

Kaufman, Y.J., Tanré, D., Remer, L., Vermote, E.F., Chu, A., \& Holben, B.N. (1997). Operational remote sensing of tropospheric aerosol over the land from EOS-MODIS. Journal of Geophysical Research, 102, 1705117068

Kaufman, Y.J., Karnieli, A., \& Tanré, D. (2000). Detection of dust over deserts using satellite data in the solar wavelengths. IEEE Transactions on Geoscience and Remote Sensing, 38, 1, 525-531

Kaufman, Y.J., Boucher, O., Tanré, D., Chin, M., Remer, L.A. \& Takemura, T. (2005). Aerosol anthropogenic component estimated from satellite data. Geophysical Research Letters, 32, 17, L17804.

Kubilay, N, Oguz, T., Kocak, M., \& Torres, O. (2005). Ground-based assessment of Total Ozone Mapping Spectrometer (TOMS) data for dust transport over the northeastern Mediterranean. Global Biogeochemical Cycles, 19, GB1022.1

Lee, J.A., Gill, T.E., Mulligan, K.R., Acosta, M.D., \& Perez, A.E. (2008). Land use/land cover and point sources of the 15 December 2003 dust storm 

in southwestern North America. Geomorphology, 105, 1-2. 18-27, doi:10.1016/j.geomorph.2007.12.016.

Legrand, M., Nertrand, J.J., Desbois, M., Menenger, L., \& Fouquart, Y. (1989). The potential of infrared satellite data for the retrieval of Saharan dust optical depth over Africa. Journal of Climatology and Applied Meteorology, 28, 309-318.

Levy, R.C., Remer, L.A., Kaufman, Y.J., Tanré, D., Mattoo, S., Vermote, E. \& O. Dubovik, (2006). Revised Algorithm Theoretical Basis Document: MODIS Aerosol Products MOD/MYD04. Available at http://modisatmos.gsfc.nasa.gov/reference_atbd.html

Levy, R.C., L.A. Remer, S. Mattoo, E.F. Vermote, \& Y.J. Kaufman (2007). Second-generation operational algorithm: Retrieval of aerosol properties over land from inversion of Moderate Resolution Imaging Spectroradiometer spectral reflectance, Journal of Geophysical Research, 112, D13211, doi:10.1029/2006JD007811

Li, J., Okin, G.S., Alvarez, L., \& Epstein, H. (2007). Quantitative effects of vegetation cover on wind erosion and soil nutrient loss in a desert grassland of southern New Mexico, USA. Biogeochemistry, 85, 3, 317332

Mackie, D.S., Boyd, P.W., Hunter, K.A., \& McTainsh, G.H. (2005). Simulating the cloud processing of iron in Australian dust: $\mathrm{pH}$ and dust concentration. Geophysical Research Letters, 32, 6, L06809

Mackie, D.S., Boyd, P.W., McTainsh, G.H., Tindale, N.W., Westberry, T.K., \& Hunter, K.A. (2008). Biogeochemistry of iron in Australian dust: from eolian uplift to marine uptake. Geochemistry, Geophysics, Geosystems. 9, doi:10.1029/2007GC001813

MacKinnon, D. J., Chavez, P. S., Jr., Fraser, R. S., Niemeyer, T. C., and Gillette, D. A., (1996), Calibration of GOES-VISSR, visible-band satellite data and its application to the analysis of a dust storm at Owens Lake, California, Geomorphology 17, pp. 229 - 250

McGowan, H.A., \& Clark, A. (2008). A vertical profile of PM10 dust concentrations measured during a regional dust event identified by MODIS Terra, western Queensland, Australia. Journal of Geophysical Research, 113, F02S03, doi:10.1029/2007JF000765. 
McTainsh, G. H. \& Strong, C.S. (2007). The role of aeolian dust in ecosystems. Geomorphology, 89, 1-2, 39-54

Mahowald, N.; Baker, A.; Bergametti, G.; Brooks, N.; Duce, R.; Jickells, T.; Kubilay, N.; Prospero, J.; Tegen, I.(2005) Atmospheric global dust cycle and iron inputs to the ocean Global Biogeochemical Cycles, Vol. 19, No. 4, GB4025,doi: 10.1029/2004GB002402, 2005

Mahowald, N., Ballentine, J.A., Feddema J., \& Ramankutty N. (2007). Global trends in visibility: implications for dust sources, Atmospheric Chemistry and Physics, 7, 3309-3339.

Mahowald, N.M., Bryant, R.G., del Corral, J. \& Steinberger, L. (2003). Ephemeral lakes and dust sources. Geophysical Research Letters, 30, 2, art.no. 1074 .

Middleton, N.J., Goudie, A.S. \& Wells, G.L. (1986). The frequency and source areas of dust storms. In Nickling, W.G. (ed) Aeolian Geomorphology. Allen \& Unwin, Boston, 237-259.

Miller, S.D. (2003). A consolidated technique for enhancing desert dust storms with MODIS. Geophysical Research Letters, 30, 20, art.no.2071.

Moorthy, K.K., Babu, S.S., Satheesh, S.K., Srinivasan, J., \& Dutt, C.B.S. (2007). Dust absorption over the "Great Indian Desert" inferred using ground-based and satellite remote sensing. Journal of Geophysical Research - Atmospheres, 112, D9, D09206.

Muhs, D.R., Budahn, J.R., Prospero, J.M., \& Carey, S.N. (2007). Geochemical evidence for African dust inputs to soils of western Atlantic islands: Barbados, the Bahamas and Florida. Journal of Geophysical Research - Earth Surface. 112, doi:10.1029/2005JF000445.

Pell, S.D., Chivas, A.R., \& Williams, I.S. (2000). The Simpson, Strzelecki and Tirari Deserts: development and sand provenance. Sedimentary Geology, 130, 1-2, 107-130.

Piketh, S.J., Tyson, P.D., \& Steffen, W. (2000). Aeolian transport from southern Africa and iron fertilization of marine biota in the South India Ocean. South African Journal of Science, 96, 244-246. 
1303

1304

1305

1306

1307

1308

1309

1310

1311

1312

1313

1314

1315

1316

1317

1318

1319

1320

Prospero, J.M., Ginoux, P., Torres, O., Nicholson, S.E. \& Gill, T.E. (2002). Environmental characterization of global sources of atmospheric soil dust identified with the Nimbus 7 Total Ozone Mapping Spectrometer (TOMS) absorbing aerosol product. Reviews of Geophysics, 40, 1, art.no.1002.

Remer, L.A., Tanré, D., Kaufman, Y.J., Levy, R. \& Mattoo, S. (2006).

Algorithm for Remote Sensing of Tropospheric Aerosol from MODIS for Collection 005 Products: 04_L2, 08_D3, 08_E3, 08_M3. Available from: http://modis-

atmos.gsfc.nasa.gov/_docs/MOD04:MYD04_ATBD_C005_rev1.pdf

Remer, L.A., Kaufman, Y.J., Tanré, D., Mattoo, S., Chu, D. A., Martins, J. V., Li, R.-R., Ichoku,, Levy, R. C., Kleidman, R. G., Eck, T. F., Vermote, E., \& Holben, B. N. (2005). The MODIS aerosol algorithm, products and validation, Journal of Atmospheric Sciences, 62, 4, 947-973.Reynolds, R., Neff, J., Reheis, M., \& Lamothe, P. (2006). Atmospheric dust in modern soil on Aeolian sandstone, Colorado Plateau (USA): variation with landscape position and contribution to potential plant nutrients. Geoderma, 130, 1-2, 108-123. 
1321 Reynolds, R., Neff, J., Reheis, M. \& Lamothe, P. (2006). Atmospheric dust in

1322 modern soil on aeolian sandstone, Colodaro Plateau (USA): variation with landscape position and contribution to potential plant nutrients. Geoderma, 130, 1-2, 108-123.

Reynolds, R., Yount, J.C., Reheis, M., Goldstein, H., Chavez, P., Fulton, R., Whitney, J., Fuller, C. \& Forester, R.M. 2007. Dust emission from wet and dry playas in the Mojave desert, USA. Earth Surface Processes and Landforms, 32, 12, 1811-1827.

Ridgwell, A.J. (2002). Dust in the Earth system: the biogeochemical linking of land, air and sea. Philosophical Transactions of the Royal Society of London, A. 360, 1801, 2905-2924.

Roskovensky, J.K. \& K.N. Liou (2003). Detection of thin cirrus from 1.38 $\mathrm{mm} / 0.65 \mathrm{~mm}$ reflectance ratio combined with $8.6-11 \mathrm{~mm}$ brightness temperature difference. Geophysical Research Letters, 30, 19, doi:10.1029/2003GL018135

Roskovensky, J.K. \& K.N. Liou (2005). Differentiating airborne dust from cirrus clouds using MODIS data. Geophysical Research Letters, 32, L12809, doi:10.1029/2005GL022798.

Satheesh, S.K. \& Moorthy, K.K. (2005). Radiative effects of natural aerosols, Atmospheric Environment, 39, 2089-2110.

Shao, Y.P., \& Wang, J.J. (2003). A climatology of northeast Asian dust events. Meterologische Zeitschrift, 12, 4, 187-196.

Shenk, W.E. \& Curran, R.J. (1974). The detection of dust storms over land and water with satellite visible and infrared measurements, Monthly Weather Review, 102, 830-837.

Schepanski, K., Tegen, I., Laurent, B., Heinold, B. \& Macke, A. (2007). A new Saharan dust source activation frequency map derived from MSGSEVIRI IR-channels. Geophysical Research Letters, 34, L18803, doi:10.1029/2007GL030168.

Soderberg, K. \& Compton, J.S. (2007). Dust as a nutrient source for fynbos ecosystems, South Africa. Ecosystems, 10, 550-561.

Sokolik, I. (2002). The spectral radiative signature of wind-blown mineral dust: implications for remote sensing in the thermal IR region. Geophysical Research Letters, 29, 2154, doi:10.1029/2002GL015910. 
1355

1356

1357

1358

1359

1360

1361

1362

1363

1364

1365

1366

1367

1368

1369

1370

1371

1372

1373

1374

1375

1376

1377

1378

1379

1380

1381

1382

1383

1384

1385

1386

1387

1388

Sprigg, R.C. (1982). Alternating wind cycles of the Quaternary era, and their influence on Aeolian sedimentation in and around the dune deserts of southeastern Australia. In Wasson, R.J. (ed). Quaternary Dust Mantles of China, New Zealand and Australia. Proceedings International Union for Quaternary Research (INQUA) Loess Commission Workshop, Canberra, 211-240.

Swap, R., Garstang, M., Greco, S., Talbot, R. \& Kallberg, P. (1992). Saharan dust in the Amazon Basin. Tellus Series B-Chemical and Physical Meteorology, 44, 2, 133-149.

Tanré, D. \& Legrand, M., (1991). On the satellite retrieval of Saharan dust optical thickness over land: Two different approaches, Journal of Geophysical Research, 96, 5221-5227.

Torres, O., Bhartia, P.K., Herman, J. R., Ahmad, Z. \& Gleason J. (1998). Derivation of aerosol properties from a satellite measurement of backscattered ultraviolet radiation: theoretical basis, Journal of Geophysical Research, 103, 17,099-17,110.

Torres, O., Tanskanen, A., Veihelmann, B., Ahn, C., Braak, R., Bhartia, P. K., Veefkind, P. \& Levelt P. (2007). Aerosols and surface UV products from Ozone Monitoring Instrument observations: an overview, Journal of Geophysical Research, 112, D24S47, doi:10.1029/2007JD008809.

Waeles, M., Baker, A.R., Jickells, T., \& Hoogewerff, J. (2007). Global dust teleconections: aerosol iron solubility and stable isotope composition. Environmental Chemistry, 4, 4, 233-237 doi:10.1071/EN07013.

Wald, A.E., Kaufman, Y.J., Tanré, D., Gao, B.C. (1998). Daytime and nighttime detection of mineral dust over desert using infrared spectral contrast. Journal of Geophysical Research-Atmospheres, 103, D24, 32307-32313.

Wang, X.B., Enema, O., Hoogmed, W.B., Perdok, U.D., \& Cai, D.X. (2006). Dust storm erosion and its impact on soil carbon and nitrogen losses in northern China. Catena, 66, 3, 221-227.

Washington, R., Todd, M., Middleton, N.J., \& Goudie, A.S. (2003). Dust-storm source areas determined by the Total Ozone Monitoring Spectrometer and surface observations. Annals of the Association of American Geographers, 93, 2, 297-313.

Page | 43 
Wolff, E.W. and 28 others. (2006). Southern Ocean sea-ice extent, productivity and iron flux over the past eight glacial cycles. Nature, 440, 7083, 491-496.

Yoshioka, M., Mahowald, N.M., Conley, A.J., Collins, W.D., Fillmore, D.W., Zender, C.S., \& Coleman, D.B. (2007). Impact of desert dust radiative forcing on Sahel precipitation: relative importance of dust compared to sea surface temperature variations, vegetation changes and greenhouse gas warming. Journal of Climate, 20, 8, 1445-1467, doi:10.1175/JCL14056.

Zha, Y., \& Li, L. (2007). Influence of the 17 April 2006 dust storm on Moderate Resolution Imaging Spectroradiometer data for land cover identification. Journal of Geophysical Research, 112, D14205, doi:10.1029/2006JD007869.

Zhang, B., Tsunekawa, A. \& Tsubo, M. (2008). Contributions of sandy lands and stony deserts to long-distance dust emission in China and Mongolia during 2000-2006. Global and Planetary Change, 60, 3-4, 487-504.

Zhu, A., Ramanthan, V., Li, F. \& Kim, D. (2007). Dust plumes over the pacific, Indian and Atlantic oceans: climatology and radiative impact. Journal of Geophysical Research - Atmospheres, 112, D16, D16208.

Zubko, V., Kaufman, Y.J., Burg, R.I. \& Martins, J.V. (2007). Principal components analysis of remote sensing of aerosols over oceans. IEEE Transactions on Geoscience and Remote Sensing, 45, 3, 730-745. 
1412

1413

1414 Figure 1. The Lake Eyre Basin of Australia, and the coverage extents of

1415 the four dust event case studies by event number.

1416

1417

1418

1419

1420

1421

1422

1423

1424

1425

1426

1427

1428

1429

1430

1431

1432

1433

1434

1435

1436

1437

1438

1440

1441

1442

\section{Figure Captions}

Figure 2. Histograms illustrating (a) the basic method for determining dust/non-dust threshold; (b) dust/non-dust thresholds derived for BTD (Ackerman, 1997) (dust < threshold; and (c) dust/non-dust threshold derived for Miller (2003) algorithm outputs (dust > threshold) for events 1-4.

Figure 3. Histograms showing the derivation of scaling factor ' $a$ ', based on reflectance ratio, for events 1-4 (graphs a-d), and BTD offset 'b' for events 1-4 (graphs e-h) necessary for applying Roskovensky \& Liou's (2005) algorithm. For event 4 the scaling factor $=0.25$ (not shown). Note: vertical axes vary.

Figure 4. Key to interpreting the colour composite combining dust/nondust detection using Ackerman (1997), Miller (2003) and Roskovensky \& Liou (2005) and shown in Figures 5-8, panel (f).

Figure 5. Event 1: 7th October 2005. Across all panels, squares highlight the prominent active dust source areas, as identified from the BTD split window product. The dust/non-dust thresholds used are detailed in Table 4. Panels (a) to (e) are derived from MODIS (Aqua) data. (a) MODIS visible (wind direction marked with arrow); (b) BTD (BT $\left.\mathrm{BT}_{11}-\mathrm{BT}_{12}\right)$; (c) threshold applied to BTD (after Ackerman, 1997); (d) Roskvensky \& Liou (2005) dust enhancement algorithm; (e) Miller's (2003) dust enhancement algorithm (dust is red); (f) Composite image of Ackerman, Miller and Roskovensky and Liou output for key see Fig.4. Panels (g) and (h) are aerosol products for the same event where (g) MYD04 Deep Blue AOT $0.1^{\circ} \times 0.1^{\circ}$ spatial resolution; (h) OMI AAl $0.25^{\circ} \times 0.25^{\circ}$ spatial resolution. 
1443 Figure 6. Event 2: 24th September 2006. Dust/non-dust thresholds used

1444 are those recommended in the published literature and the same as those

1445 used for Event 1.

1446

1447 Figure 7. Event 2: 24th September 2006. Dust/non-dust thresholds used

1448 are specific to Event 2 and adjusted using the histogram approach (Figure 3).

1450 Figure 8. Event 3: 2nd February 2005. For panel explanations see Figure

1451 5. Dust/non-dust thresholds used are specific to Event 3 and adjusted using

1452 the histogram approach (Figure 3)

1453

1454 Figure 9. Event 4: $30^{\text {th }}$ August 2005. For panel explanations see Figure 5.

1455 Dust/non-dust thresholds used are specific to Event 4 and adjusted using the

1456 histogram approach (Figure 3)

1457

1458 Figure 10. Summary of the relationships between the methods and

1459 approaches discussed in this paper.

1460

1461

Page | 46 
1461 Table 1. Spatial and temporal characteristics of remote sensing data used in 1462 this study.

1463

\begin{tabular}{|c|c|c|c|c|}
\hline Data Type & $\begin{array}{c}\text { Spatial Resolution at } \\
\text { Nadir }(\mathrm{km})\end{array}$ & $\begin{array}{l}\text { Scenes } \\
\text { used per } \\
\text { day }\end{array}$ & $\begin{array}{l}\text { Archive } \\
\text { Length }\end{array}$ & $\begin{array}{c}\text { Typical Overpass: } \\
\text { (am/pm) }\end{array}$ \\
\hline MOD02 & $0.25 \times 0.25\left(\mathrm{VIS}^{1}\right)$ & 1 & 1999 - date & $\operatorname{am}(10: 30)$ ect $^{\dagger}$ \\
\hline \multirow[t]{2}{*}{ [Terra] } & $0.5 \times 0.5\left(\mathrm{VIS}+\mathrm{NIR}^{2}\right)$ & & & \\
\hline & $1 \times 1\left(\mathrm{TIR}^{3}+\right.$ all bands $)$ & & & \\
\hline MYD02 & $0.25 \times 0.25$ (VIS) & 1 & 2002 - date & pm (13:30) ect \\
\hline \multirow[t]{2}{*}{ [Aqua] } & $0.5 \times 0.5(\mathrm{VIS}+\mathrm{NIR})$ & & & \\
\hline & $1 \times 1$ (TIR + all bands $)$ & & & \\
\hline MYD04 & $10 \times 10$ & 1 & 2002 - date & pm (13:30) ect \\
\hline \multicolumn{5}{|l|}{ [Deep Blue] } \\
\hline OMI & $13 \times 24$ & 1 & 2004 - date & $\mathrm{pm}(13: 38)$ ect \\
\hline
\end{tabular}

$1464 \quad{ }^{1}$ Visible; ${ }^{2}$ Near-infrared; ${ }^{3}$ Thermal-infrared; ${ }^{\dagger}$ Equatorial crossing time

1465

1466

1467 
1467 Table 2. Summary of dust event case studies used in this study to evaluate

1468 MODIS dust detection algorithms

1469

\begin{tabular}{|c|c|c|c|c|c|}
\hline Event & $\begin{array}{c}\text { Date } \\
\text { DD/MM/YY } \\
\text { (Julian) }\end{array}$ & $\begin{array}{c}\text { Satellite } \\
\text { overpass time } \\
\text { (UTC) }\end{array}$ & $\begin{array}{l}\mathrm{BoM}^{\dagger} \text { stations } \\
\text { recording } \\
\text { visibility } \leq 1 \mathrm{~km}\end{array}$ & $\begin{array}{l}\text { Selection } \\
\text { Criteria }\end{array}$ & $\begin{array}{c}\text { Synoptic } \\
\text { Conditions }\end{array}$ \\
\hline 1 & $\begin{array}{c}07 / 10 / 05 \\
(2005: 280)\end{array}$ & $\begin{array}{l}\text { AQUA (01:35) } \\
\text { AURA }(01: 46)\end{array}$ & 1 & $\begin{array}{c}\text { Dust and } 30 \% \\
\text { cloud cover }\end{array}$ & $\begin{array}{l}\text { Pre-frontal } \\
\text { northerly }\end{array}$ \\
\hline 2 & $\begin{array}{c}\text { 24/09/06 } \\
(2006: 267)\end{array}$ & $\begin{array}{l}\text { AQUA }(04: 20) \\
\text { AURA }(04: 31)\end{array}$ & 2 & $\begin{array}{l}\text { Dust - Single } \\
\text { frontal plume }\end{array}$ & $\begin{array}{c}\text { Post-frontal } \\
\text { southerly }\end{array}$ \\
\hline 3 & $\begin{array}{c}\text { 02/02/05 } \\
(2005: 033)\end{array}$ & $\begin{array}{l}\text { AQUA }(04: 10) \\
\text { AURA }(04: 21)\end{array}$ & 35 & $\begin{array}{l}\text { Dust - Multiple } \\
\text { plumes and } \\
\text { source types }\end{array}$ & $\begin{array}{l}\text { Post-frontal } \\
\text { southerly }\end{array}$ \\
\hline 4 & $\begin{array}{c}\text { 30/08/05 } \\
(2005: 242)\end{array}$ & $\begin{array}{l}\text { AQUA }(04: 50) \\
\text { AURA }(05: 01)\end{array}$ & 1 & $\begin{array}{c}\text { Dust and } 50 \% \\
\text { cloud cover }\end{array}$ & $\begin{array}{c}\text { Pre-frontal } \\
\text { northerly }\end{array}$ \\
\hline
\end{tabular}

1470

${ }^{\dagger}$ Bureau of Meteorology

1471

1472

1473 
1473 Table 3. Summary of dust detection algorithms applied to MODIS L1B

1474 data in this study

1475

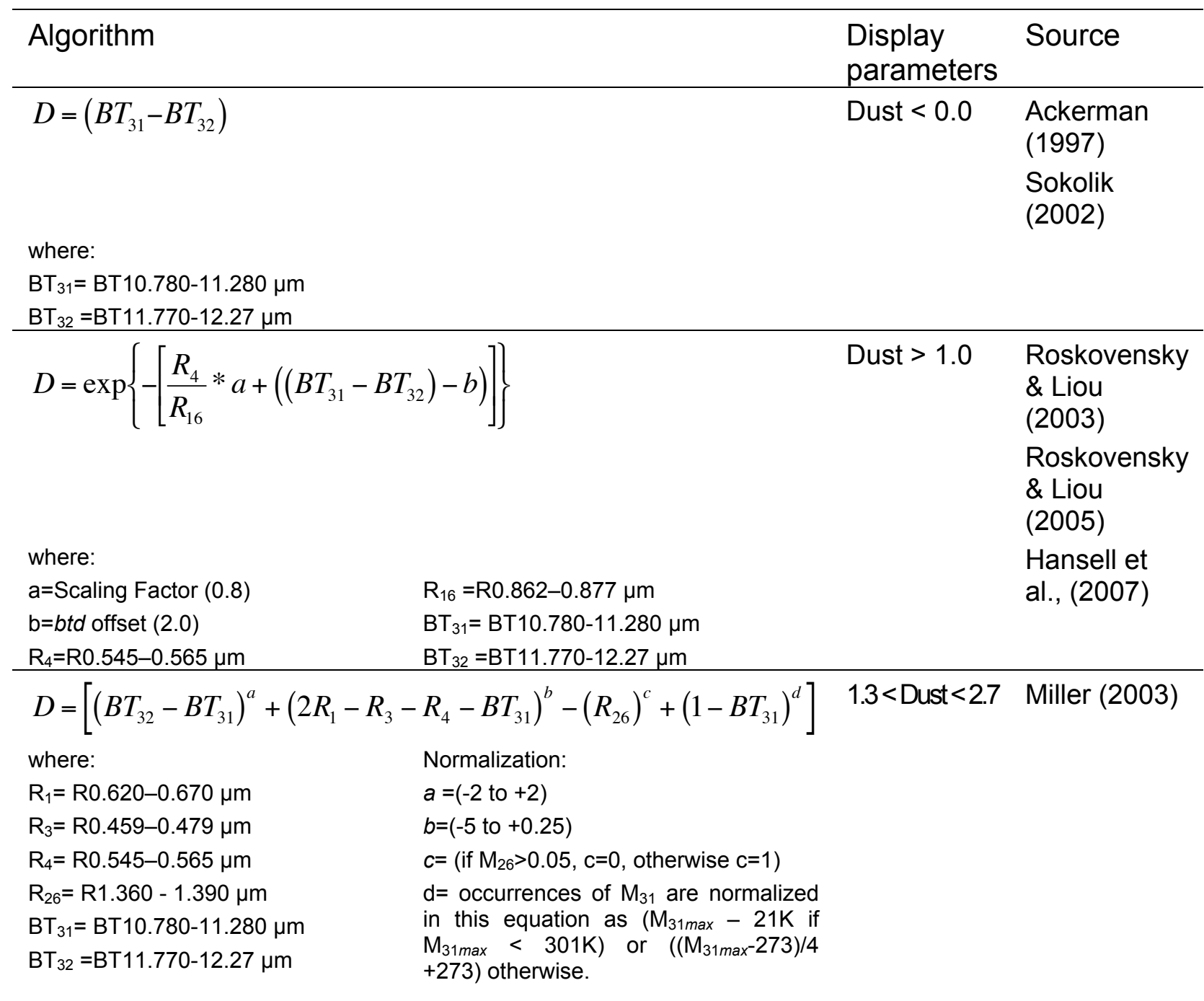

1476

1477

1478 
1478 Table 4. Comparison of recommended dust/non dust thresholds and

1479 thresholds identified for events

1480 described in this study.

1481

1482

\begin{tabular}{|c|c|c|c|c|c|}
\hline \multirow[t]{3}{*}{ Technique } & \multirow{3}{*}{$\begin{array}{l}\text { Suggested } \\
\text { threshold } \\
\text { values }\end{array}$} & \multicolumn{4}{|c|}{ Dust/non-dust thresholds } \\
\hline & & Event 1 & Event 2 & Event 3 & Event 4 \\
\hline & & 7 Oct 2005 & 24 Sept 2006 & 2 Feb 2005 & 30 Aug 200! \\
\hline $\begin{array}{l}\text { Ackerman } \\
\text { (1997) }\end{array}$ & Dust $<0.0$ & Dust $<0.0$ & Dust $<0.0$ & Dust $<-1.2$ & Dust $<-0.3$ ? \\
\hline Miller (2003) & $\begin{array}{c}1.3<\text { Dust } \\
<2.7\end{array}$ & $\begin{array}{c}1.3<\text { Dust }< \\
2.27^{*}\end{array}$ & $\begin{array}{c}-0.55<\text { Dust } \\
<1.11^{*}\end{array}$ & $\begin{array}{c}0.3<\text { Dust }< \\
2.05^{\star}\end{array}$ & $\begin{array}{c}0.45<\text { Dust } \\
1.08^{*}\end{array}$ \\
\hline $\begin{array}{l}\text { Roskovensky } \\
\text { \& Liou (2005) }\end{array}$ & $\begin{array}{l}\text { Dust }>1.0 \\
\begin{aligned} a= & 0.8, b \\
& =2\end{aligned}\end{array}$ & $\begin{array}{c}\text { Dust }>1.0 \\
a=0.8, b=1\end{array}$ & $\begin{array}{c}\text { Dust }>1.0 \\
a=0.9, b=- \\
0.5\end{array}$ & $\begin{array}{c}\text { Dust }>1.0 \\
a=1.2, b=-0.5\end{array}$ & $\begin{array}{l}\text { Dust }>1.0 \\
a=0.25, b=c\end{array}$ \\
\hline
\end{tabular}

1483

*upper value is scene maximum

1484

1485 
Figure 1

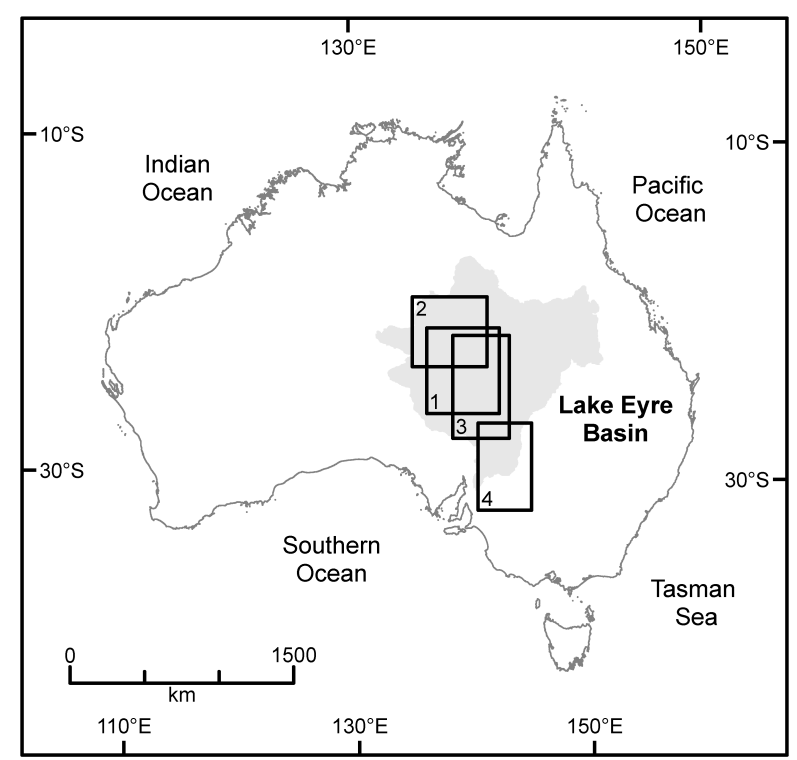

1486

1487

1488

Page | 51 
1488 Figure 2

1489
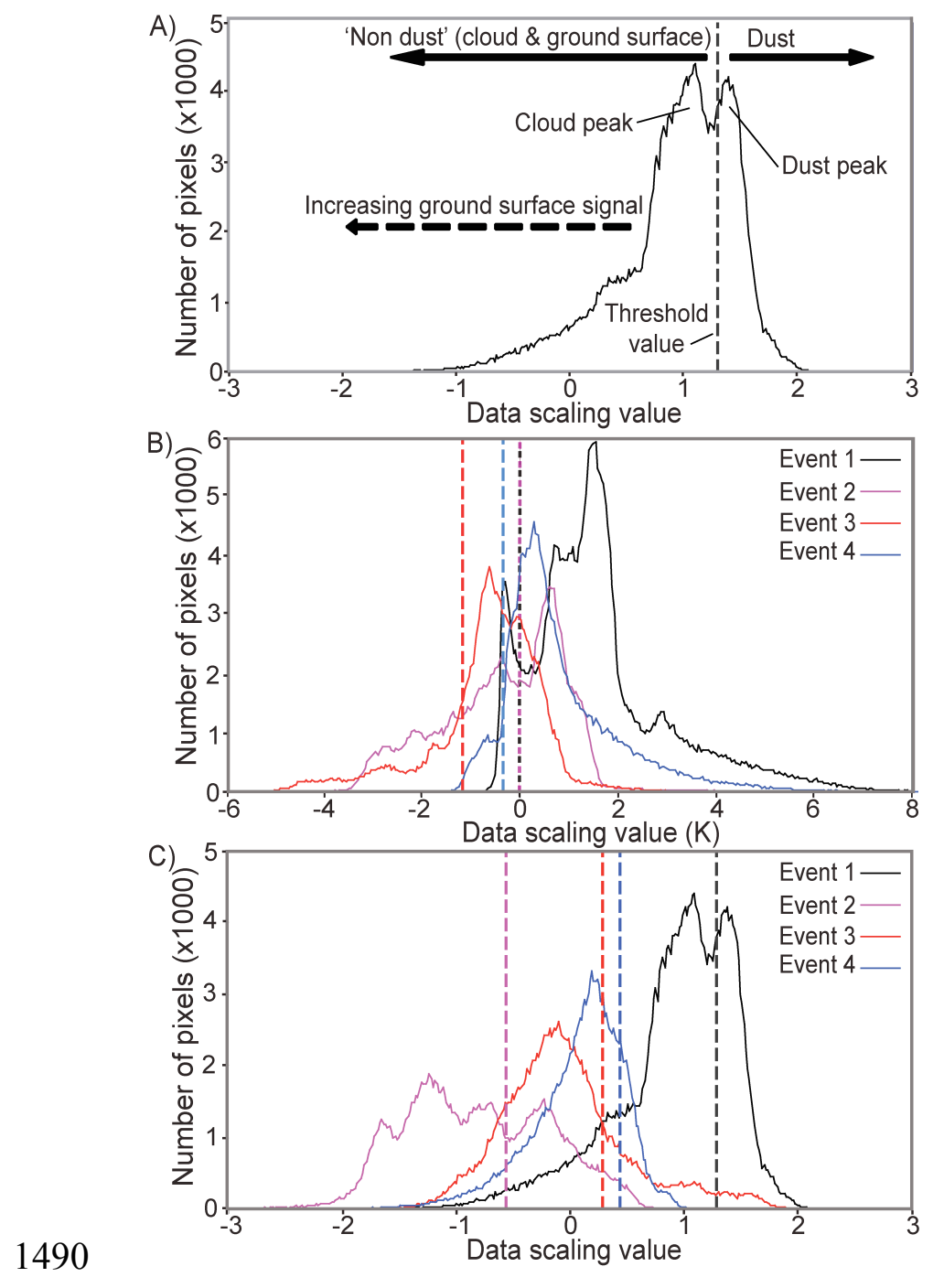

1491

1492 
1493
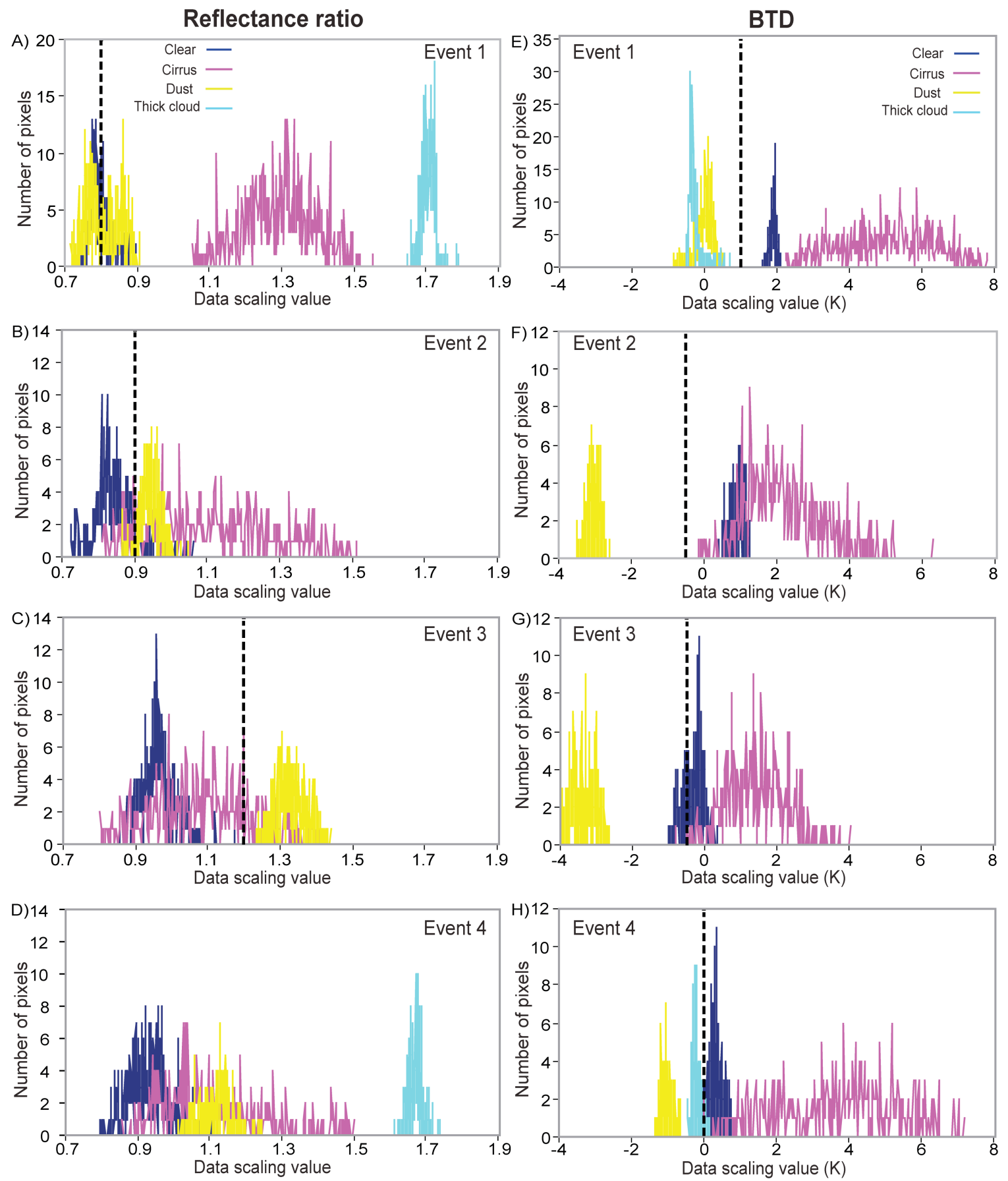
Figure 4

\begin{tabular}{|c|c|c|c|c|}
\hline & \multicolumn{3}{|c|}{ Dust pixels } \\
\hline & & A & M & $R \& L$ \\
\hline \multirow{3}{*}{$\begin{array}{l}\text { Dust } \\
\text { pixels }\end{array}$} & A & & & \\
\hline & M & & & \\
\hline & $R \& L$ & & & \\
\hline \multicolumn{2}{|c|}{$\begin{array}{l}\text { ALL indicate dust } \\
\text { pixels }\end{array}$} & & & \\
\hline \multicolumn{2}{|c|}{$\begin{array}{l}\text { ALL indicate non- } \\
\text { dust pixels }\end{array}$} & & & \\
\hline
\end{tabular}


Figure 5

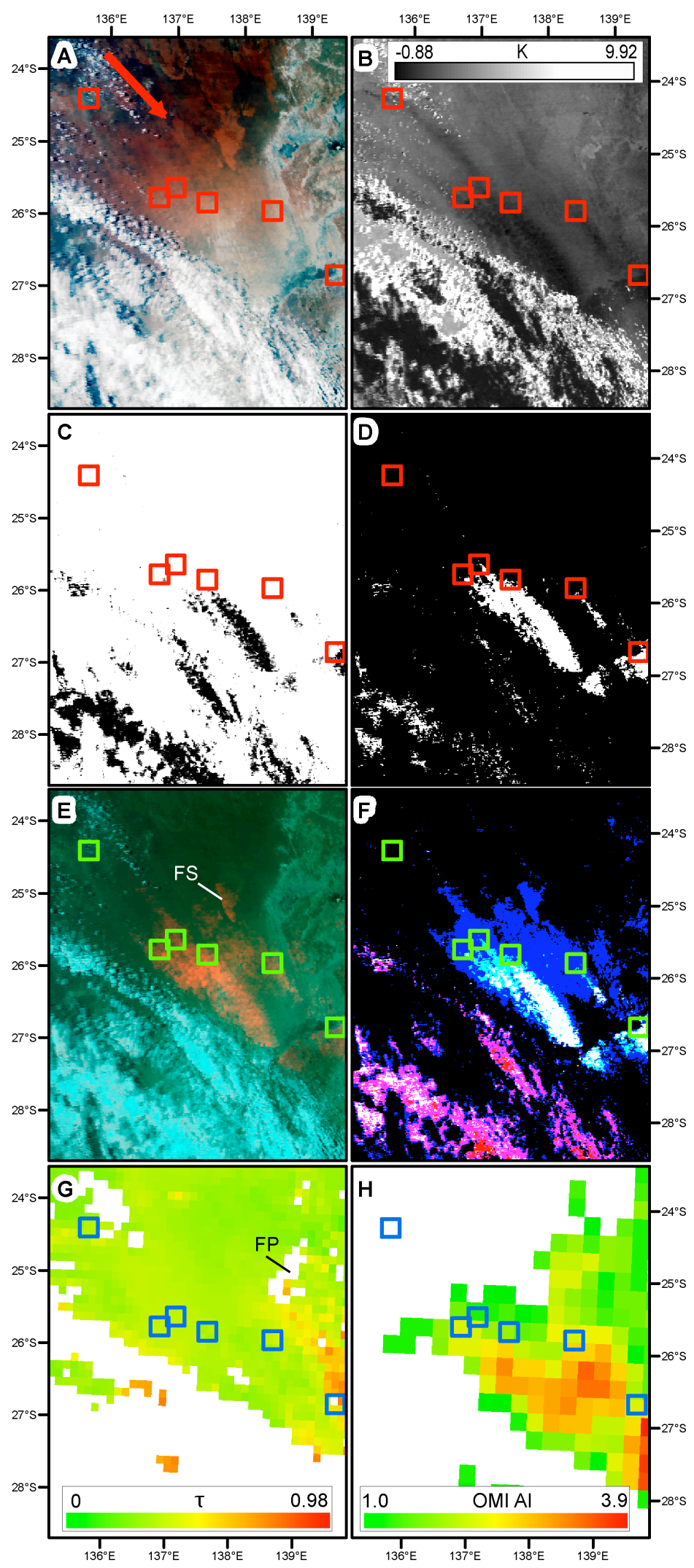

1497

1498 
1498 Figure 6

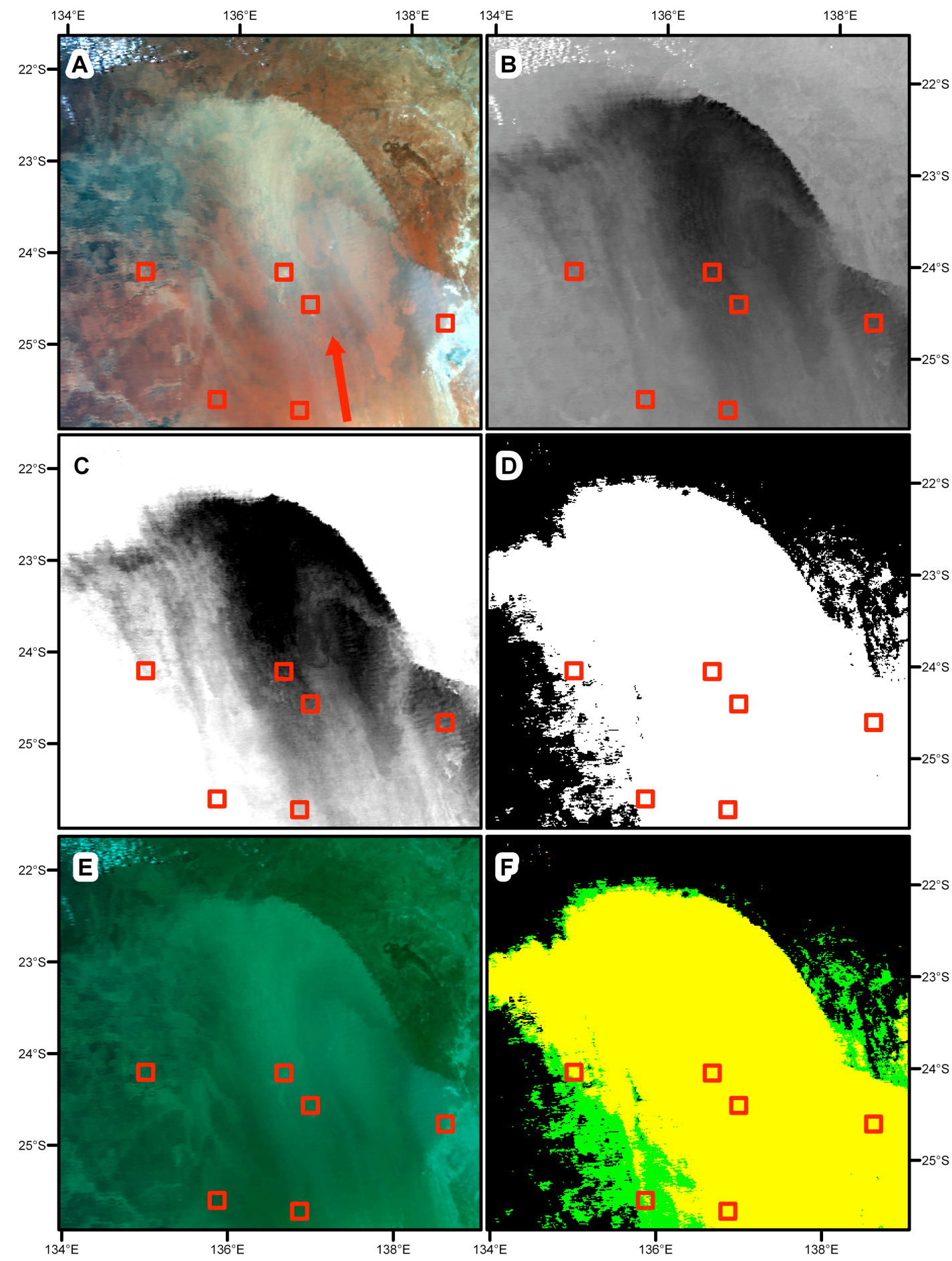

1499

1500 
$1500 \quad$ Figure 7

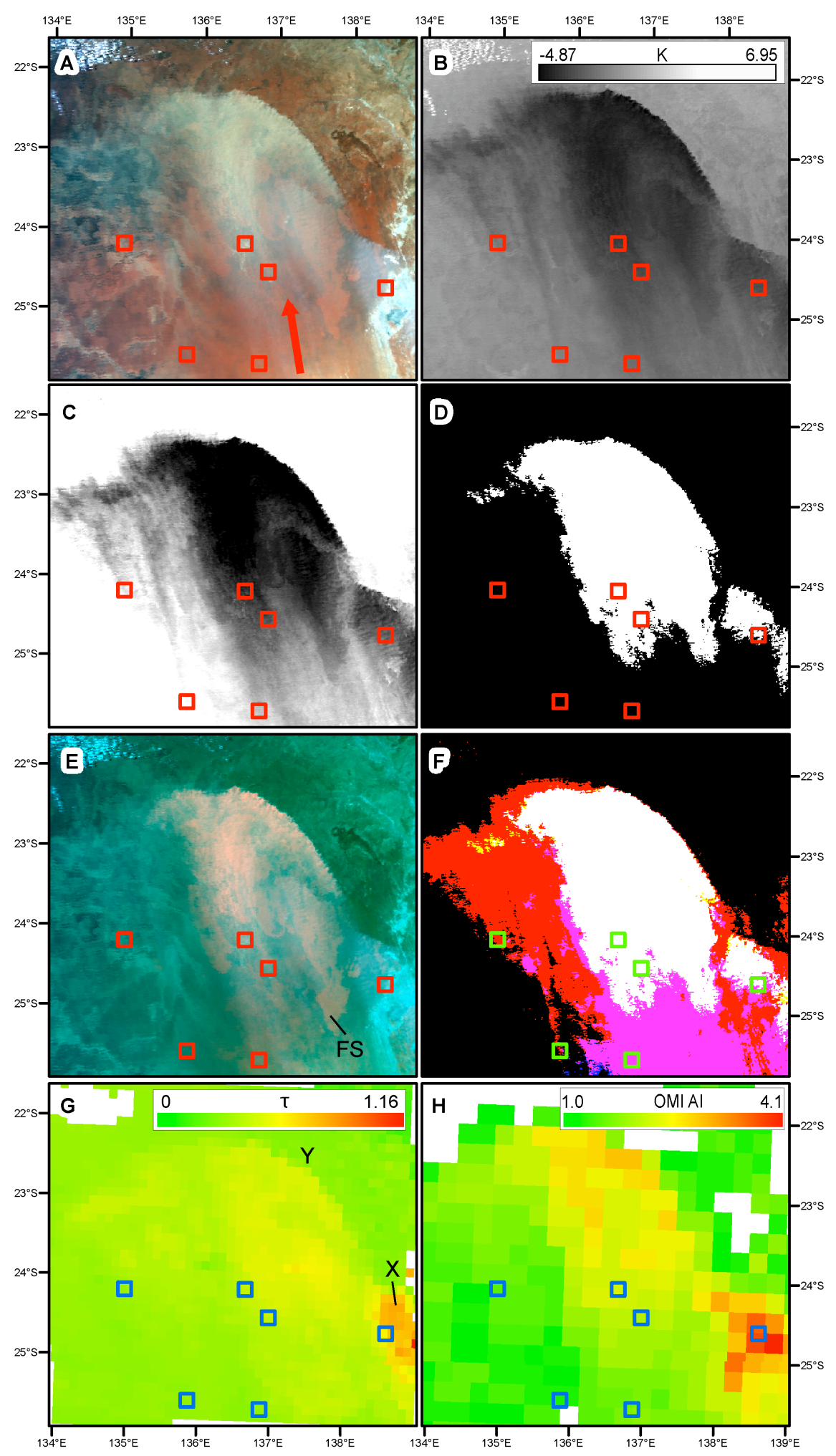

1501 
Figure 8

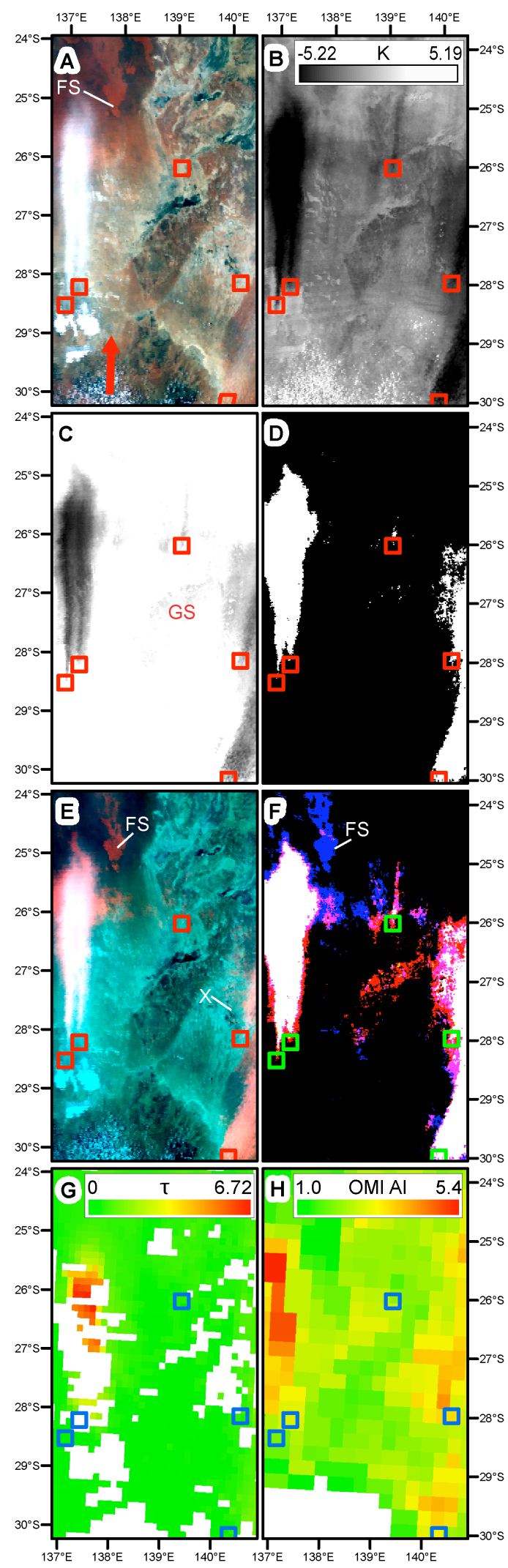

Page | 58 
Figure 9

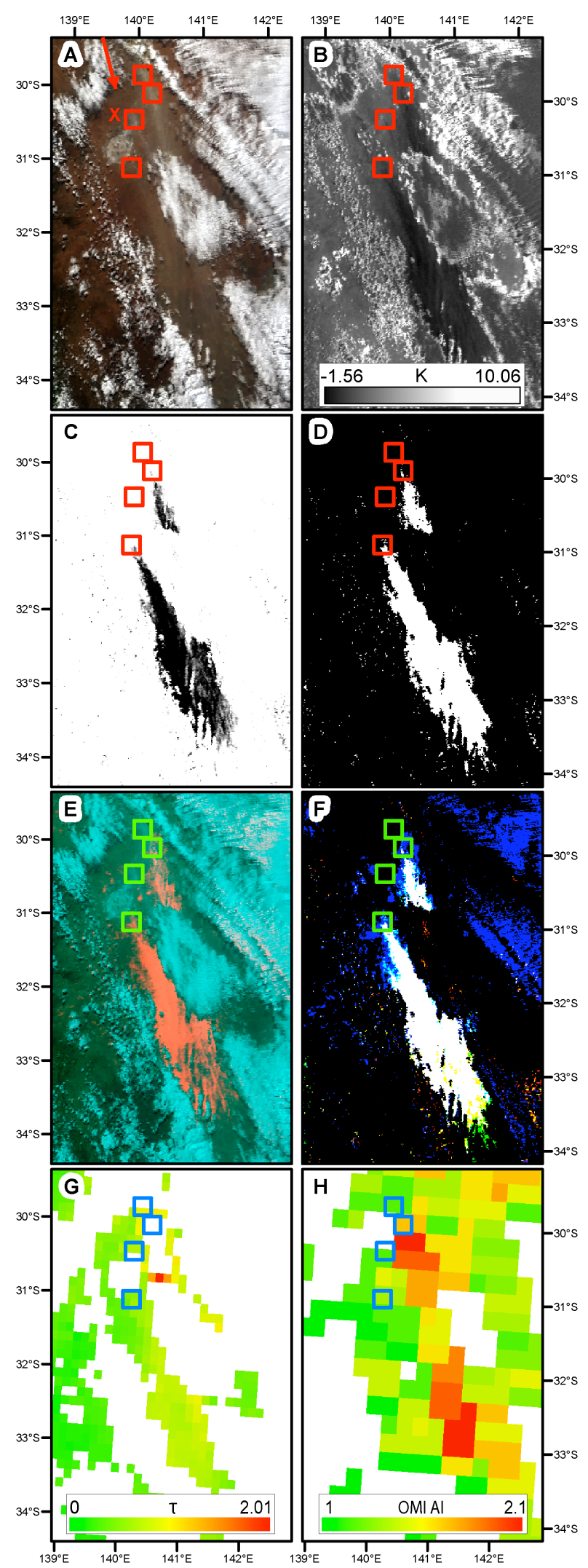




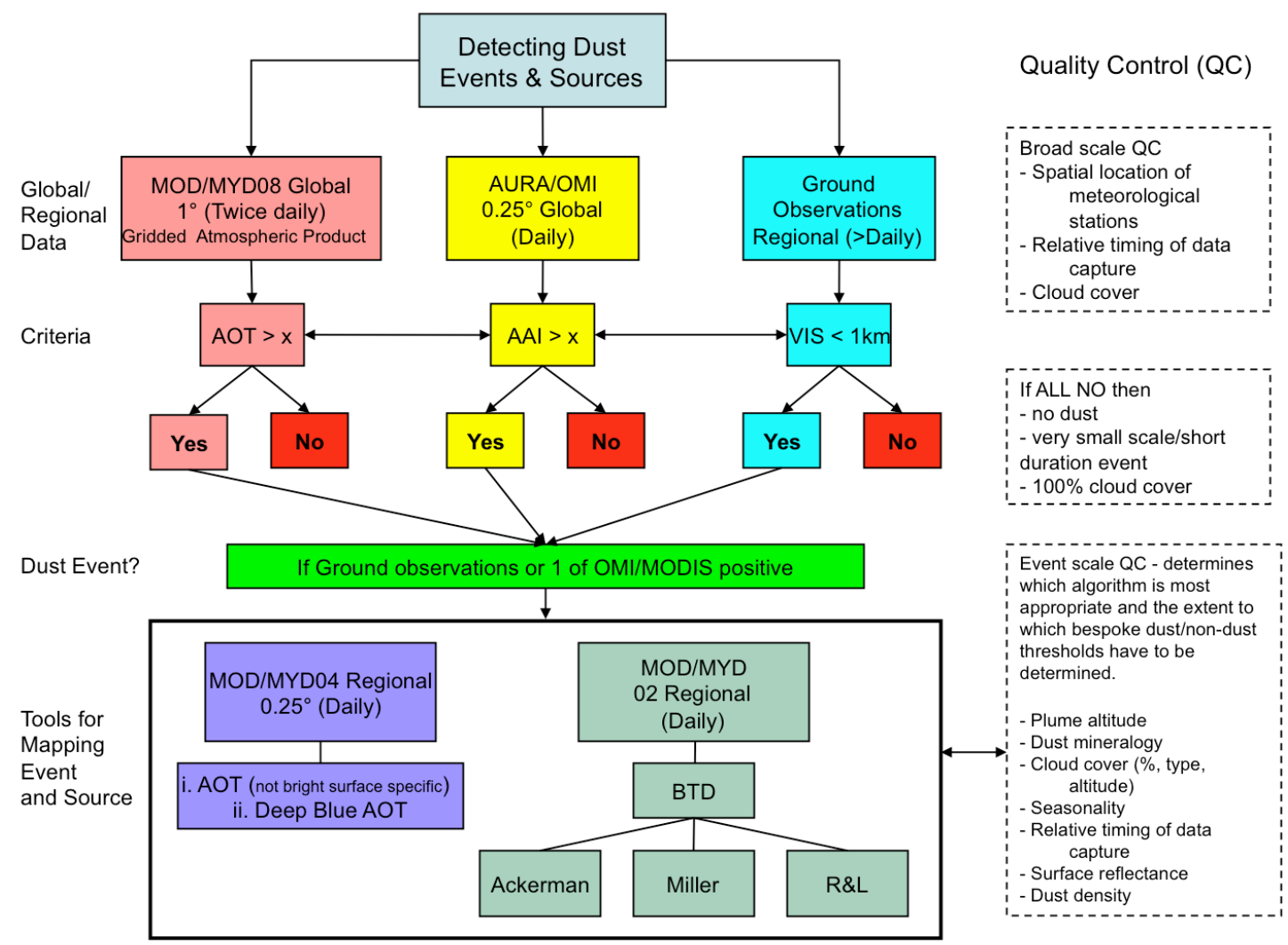

